SF 253

. A6

1917

DAIRY LABORATORY

MANUAL AND NOTE BOOK

ERNEST L.ANTHONY,B.S.A.,M.S. 


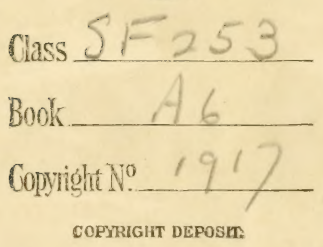




\section{DAIRY LABORATORY MANUAL AND NOTE BOOK}




\section{LIPPINCOTT'S FARM MANUALS}

Edited by K. C. DAVIS, Ph.D.

PRODUCTIVE SWINE HUSBANDRY

By GEORGE E. DAY, B.S.A.

PROF. OF ANIMAL HUSBANDRY, ONTARIO AGRICULTURAL COLLEGE, CANADA. 96 illustrations. xiii +363 pages.

$\$ 1.75$ net.

SECOND EDITION REVISED

PRODUCTIVE POULTRY HUSBANDRY

BY HARRY R. LEWIS, B.S.

POULTRY HUSBANDRYMAN, NEW JERSEY AGRICULTURAL.

EXPERIMENT STATION.

330 illustrations. $x x i+536$ pages.

$\$ 2.00$ net.

PRODUCTIVE HORSE HUSBANDRY

By CARL W. GAY, B.S.A.

PROF. ANIMAL HUSBANDRY, CHAIRMAN ANIMAL HUSBANDRY SECTION, DEPARTMENT OF AGRICULTURE,

UNIVERSITY OF MINNESOTA.

I76 illustrations. $\quad x v i+33 I$ pages.

$\$ 1.75$ net.

PRODUCTIVE ORCHARDING

BY FRED C. SEARS, M.S.

PROF, OF POMOLOGY, MASSACHUSETTS AGRICULTURAL COLLEGE.

I57 illustrations. $\quad$ xiv +314 pages. \$I.75 net.

PRODUCTIVE VEGETABLE GROWING

By JOHN W, LLOYD, M.S.A.

PROF. OF OLERICULTURE, UNIVERSITY OF ILLINOIS.

I94 illustrations. xiii +339 pages. \$I.75 net.

SECOND EDITION REVISED AND ENLARGED

PRODUCTIVE FEEDING OF FARM ANIMALS

By F. W. WOLL, Ph.D.

PROF, OF ANIMAL NUTRITION, UNIVERSITY OF CALIFORNIA.

Io6 illustrations. $\quad x i i+375$ pages.

$\$ 1.75$ net.

SECOND EDITION

COMMON DISEASES OF FARM ANIMALS

By R. A. CRAIG, D.V.M.

PROF, VETERINARY SCIENCE, PURDUE UNIVERSITY.

124 illustrations. $x i i+334$ pages.

$\$ 1.75$ net.

PRODUCTIVE FARM CROPS

By E. G. MONTGOMERY, M.A.

PROF. OF FARM CROPS, CORNELL UNIVERSITY.

204 illustrations. $x i x+50 I$ pages.

$\$ 1.75$ net.

PRODUCTIVE BEE KEEPING

By FRANK C. PELLETT

STATE APIARIST OF IOWA.
xiv +302 pages.

$\$ 1.75$ net.

IN PREPARATION

PRODUCTIVE DAIRYING

By R. M. WASHBURN

PROF, OF DAIRY HUSBANDRY, UNIVERSITY OF MINNESOTA.

132 illustrations. xii +393 pages.

$\$ 1.75$ net. 


\section{DAIRY LABORATORY MANUAL AND NOTE BOOK}

COMPILED BY

ERNEST L. ANTHONY, B.S.A., M.S.

ASSISTANT PROFESSOR IN DAIRI HUSBANDRY, THE PENNSYLVANIA STATE COLLEGE

15 ILLUSTRATIONS IN THE TEXT

SECOND EDITION REVISED

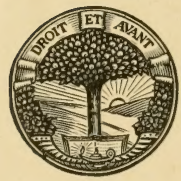

PHILADELPHIA AND LONDON

J. B. LIPPINCOTT COMPANY 


\section{$\mathrm{SF}_{253}$ \\ - A6 \\ 1917}

COPYRIGHT, I9I4, BY J. B. LIPPINCOTT COMPANY

COPYRIGHT, I9I7, BY J. B. LIPPINCOTT COMPANY

Electrotyped and Printed by J. B. Lippincott Company At the Washington Square Press, Philadelphia, U. S. A.

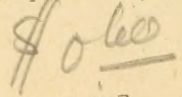

MAY 101917

(C) $\mathrm{Cl} 4460668$

no 1 


\section{PREFACE}

The following exercises have been arranged especially for general courses in the Elements of Dairying. A number of these exercises have been used in separate form and have been brought together for courses of this nature. They are designed to cover the use of the Babcock Tester, Lactometer, and special work with Farm Separators and Churns. They have all been used by the writer in class work, a number of them were recommended by the Committee on the Courses of Study of the Official Dairy Instructors' Association.

These exercises are designed to be used with courses having two or more hours' laboratory practice each week, and should familiarize the student sufficiently with the general practice so that he may be able to handle the more advanced courses in testing and creamery work. The exercises are on separate pages so that the book may be used as a note book, and all answers and notations can be made while the student is in the laboratory.

Ernest L. Anthony

Pennsylvania State College, January 1, 1914 



\section{CONTENTS}

PAGE

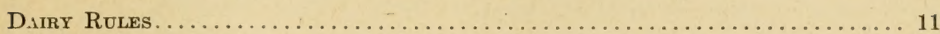

Rules for Standardization . . . . . . . . . . . . . . 12

Exercise 1.-Object: To Determine the Physical Differences between Milk, Cream and Skimmilk . . . . . . . . . . . . . . . . . . . . 15

Exercise 2.-Object: To Determine the Accuracy of the Calibration of the Glassware Used for the Babcock Test. . . . . . . . . . . . . . . . . . . . . . . 16

Exercise 3.-Object: To Determine the Accuracy of the Calibration of the Glassware Used for the Babcock Test by the Trowbridge Plug Method; also a Method for Washing up Glassware. . . . . . . . . . . . . . . . . . . 18

Exercise 4.-Object: To Make a Test of Milk for Butterfat by the Babcock Method. 20

Exercise 5.-Object: To Test Whole Milk for Fat Content by Babcock Method . . . 22

Exercise 6.-Object: To Test Cream for Fat Content by Babcock Method ... . . . 23

Exercise 7.-Object: To Test Cream for Fat Content by Babcock Method... . . . 24

Exercise 8.-Object: To Determine the Percentage of Fat in Skimmilk and Whey ... 25

Exercise 9.-Object: To Determine the Percentage of Fat in Buttermilk........26

Exercise 10.-Object: To Determine the Specific Gravity of Milk............ 27

Exercise 11.-Object: To Determine the Total Solids and the Solids not Fat in Milk. . 29

Exercise 12.-Object: To Determine the Specific Gravity and Adulteration of Milk... 30

Exercise 13.-Object: To Determine the Effect of not Mixing a Sample Previous to Testing . . . . . . . . . . . . . . . . . . . . . . 32

Exercise 14.-Object: To Determine Effect of Temperature when Reading the Fat Test. . . . . . . . . . . . . . . . . . . . 33

Exercise 15.-Object: To Determine the Effect of Speed of the Tester upon the Test. . 34

Exercise 16.-Object: To Determine the Effect of Varying Amounts of Acid in the Babcock Test. . . . . . . . . . . . . . . . . . . . . 35

ExERcise 17.-Object: To Determine the Effect of Temperature of Milk and Incomplete Mixing of Acid and Milk . . . . . . . . . . . . . . 36

Exercise 18.-Object: To Determine the Effect of Measuring Cream as Compared

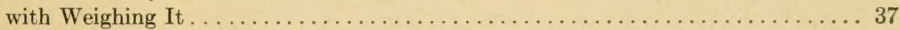

Exercise 19.-Object: To Determine the Effect of Adding Water before Whirling in the 9 -gram Cream Test . . . . . . . . . . . . . . . . . . . . 38

Exercise 20.-Object: To Test Butter for Percentage of Fat............... 39 


\section{CONTENTS-CONTINUED}

Exercise 21. Object: To Note the Acidity of Milk Products, and to Compare the Method of Determining the Acidity . . . . . . . . . . . . . . . . . . . 40

Exercise 22.-Object: To Standardize Milk and Cream ................. 42

Exercise 23.-Object: To Prepare a Commercial Starter ................. 43

Exercise 24.-Object: To Learn the Correct Use of Milk Coolers.............. 44

Exercise 25.-Object: To Make a Comparative Study of Cream Separators ....... 45

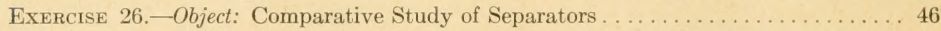

Exercise 27.-Object: To Determine the Capacity of Separators ............ 47

Exercise 28.-Object: To Adjust Height of Bowl and Position of Cream Screw . . . . 48

Exercise 29.-Object: To Determine the Effect of Speed Variations on the Proportion of Cream, Richness of Cream, and on the Loss of Fat in Skimmilk . . . . . . . . 49

ExERcise 30.-Object: To Determine the Influence of the Change of Inflow on the Proportion and Richness of Cream, and the Loss of Fat in the Skimmilk...... 50

Exercise 31.-Object: To Determine the Effect of Variations in Temperature of Milk and Proportion and Richness of Cream and Loss of Fat............... 51

Exercise 32.-Object: To Churn Butter from Ripened Cream. (First Churning Ex-

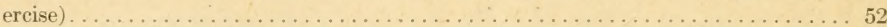

Exercise 33.-Object: To Churn and Make a Good Grade of Butter from Well Ripened Cream. (Second Churning Exercise) ......................... 54

Exercise 34.-Object: To See the Effect of Churning at a High Churning Temperature and Washing at a Low Temperature........................ 55

Exercise 35.-Object: To See the Effects of a Low Churning Temperature and a High Washing Temperature ............................... 56

Exercise 36.-Object: To Determine the Effect of Churning very Thick Cream ..... 57

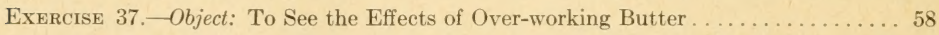

Exercise 38.-Object: To Note the Effect of Over-churning on the Quality of the Butter Produced . . . . . . . . . . . . . . . . . . . . . . . . . . 60

Exercise 39.-Object: The Effect of Churning Cream at Different Stages of Ripening 62

Exercise 40 -Object: The Scoring of Butter ...................... 64

Exercise 41.-Object: To Determine the Percentage of Water in Butter.......... 65

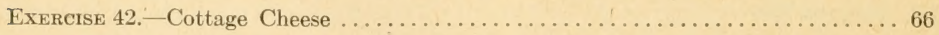

ExERCise 43.-Cross Section of Cream Separator Bowl . . . . . . . . . . . . . 70

Dairy Arithmetic Problems . . . . . . . . . . . . . . . . . . . . . . . 


\section{ILLUSTRATIONS}

Whole Milk Bottle . . . . . . . . . . . . . . . . . . . $\ldots \ldots \ldots \ldots$

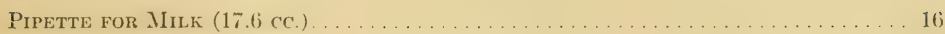

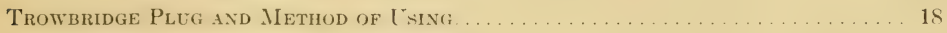

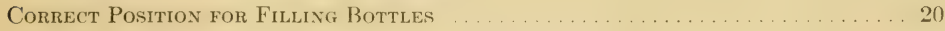

Correct Manner of Taking Reading with Calipers . . . . . . . . . . . . . 20

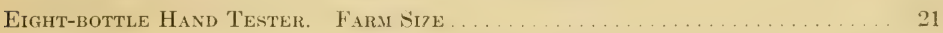

Correct Method of Taking Reading on Whole Milk Bottles. From the Extreme Lower Meniscus to the Top of the Upper Meniscus . . . . . . . . . 21

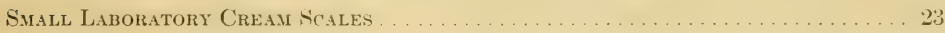

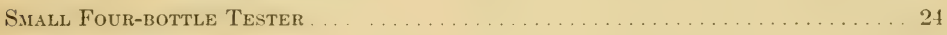

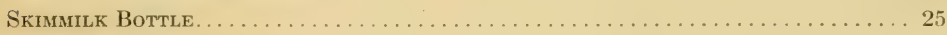

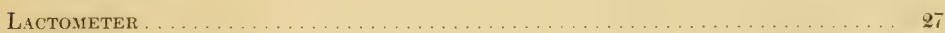

Lactometer Cylinder. . . . . . . . . . . . . . . . . . . . . . . .

Apparatus for ACID Test. . . . . . . . . . . . . . . . . . . 40

Farrington's Acid Test Apparates. . . . . . . . . . . . . . . . . . 40

Spring Balance for Weighing Milk . . . . . . . . . . . . . . . 47 


\section{DEFINITIONS}

Definition for Milk,-Normal milk is a liquid secreted by all healthy females of the mammalian group, for feeding their offspring.

Definition for Specific Gravity.-The specific gravity of a substance is the relation between the weight of that substance and the weight of an equal volume of distilled water. Water is always considered as one, or the unit, with which liquids and solids of the same temperature are compared. Examples:

1 gallon of water weighs $8.3 \mathrm{lbs}$. Specific Gravity 1.

1 gallon of milk weighs $8.55 \mathrm{lbs}$.

$\begin{array}{ccc}\text { " } & \text { " } & 1.032 \\ \text { " } & \text { " } & .93 \\ \text { " } & \text { " } & 1.034 \\ & & 1.012\end{array}$

$\begin{array}{lllc}1 \text { gallon of butterfat weighs } 7.7 \mathrm{lbs} \text {. } & \text { " } & \text { " } & .93 \\ 1 \text { gallon of shimmilk weighs } 8.58 \text { lbs. } & \text { " } & \text { " } & 1.034 \\ 1 \text { gallon of } 20 \text { per cent cream weighs } 8.44 \text { lbs. } & \text { " } & \text { " } & 1.012\end{array}$

Definition of Centrifugal Force.-Centrifugal force is the outward pull or pressure brought on a wheel or object when rotating and being whirled from the centre. The centrifugal force is increased $(a)$ directly in proportion to the decrease in the diameter (the velocity remaining the same), and (b) directly with the square of the velocity (diameter being constant). 


\section{DAIRY LABORATORY MANUAL AND NOTE BOOK}

\section{DAIRY RULES.}

1. Rule for determining the number of pounds of butterfat in a given amount of cream or milk when the percentage of fat is given.

Multiply the percentage of butterfat by the pounds of milk and divide by 100 (i.e., point off two places).

2. Rule for determining the percentage of casein in milk when the percentage of fat is known. (Van Slyke.)

Subtract 3 from the percentage of fat in milk, multiply the remainder by .4 and add 2.1 to the result.

Milk with 4.8 per cent fat has 2.82 per cent casein $[(4.8-3) \times .4+2.1=$ 2.82].

3. Rule for determining the price per pound received for butterfat in cream when the percentage of fat and the price per gallon are given.

Multiply the pounds of cream in a gallon by the percentage of fat given (point off two places). This will give the pounds of fat one gallon of cream contains. Divide the number representing the price per gallon of cream by the number of pounds of butterfat, the quotient will equal the price per pound of butterfat.

4. Rule for determining the price of a gallon of cream when it is being paid for on the butterfat basis.

Multiply the percentage of fat in the cream by the pounds of cream in a gallon (point off two places). This will give the number of pounds of fat in a gallon. Multiply this by the price per pound paid for fat.

5. Rules for finding the percentage of solids not fat.

Rule A.-(A rough practical rule.) The (Quevenne) lactometer reading plus the percentage of fat divided by 4 equals the solids not fat.

Rule B.-(Accurate rule, recommended for accurate work.)

One fourth of the (Quevenne) lactometer reading plus .2 times the fat equals the solids not fat.

If the lactometer reading is 31 and the fat is 3.8 per cent the solids not fat equal 8.51 per cent. $(31 \div 4+.2 \times 3.8=8.51$. $)$ 
6. Rule for finding the percentage of acid by Mann's acid test.

Multiply the number of ec. of alkali solution used, by .009 and divide the product by the number of ce. of the sample tested, the quotient when multiplied by 100 will give the percentage.

7. Rule for finding the percentage of overrun in butter.

Subtract from the butter made, the pounds of fat in the cream used. Divide the result by the butterfat in the cream and multiply by 100 . This equals the percentage of actual overrun.

If 450 pounds of butter is made from cream containing 400 pounds of fat, the pounds of overrun is $(450-400=50)$. The pereentage is $[(50 \div 400) \times$ $100=] 12.5$ per cent.

8. To find the correct specific gravity of a sample when the temperature is other than $60^{\circ} \mathrm{F}$.

Add one-tenth of a per cent to the reading for each degree above $60^{\circ}$, and subtract one-tenth for each degree below $60^{\circ}$.

\section{RULES FOR STANDARDIZATION.}

In many cases it is necessary to change the per cent fat in milk or cream to some other known per cent fat. This is called standardizing. In much standardization work it is necessary to find the relative amount of two different milks or ereams of different percentages of fat to make a certain amount of standardized milk or cream of a known per cent of fat. This is found by:

9. Subtracting the difference between the fat desired in the standardized milk, and the milk of the lower fat content; and by subtracting the difference between the percentage of fat in the milk of the lower fat content and the percentage of fat in the milk or cream of the higher fat content. The first result when divided into the last will give the percentage of the amount wanted which must be used of the milk or cream of the higher fat content. This amount taken from the total amount wanted will give the amount of the lower milk or cream to be used, as:

100 pounds of 3.5 per eent milk is desired. It is to be made from milk testing 3 per cent and milk testing 5 per cent.

$3.5-3=.5 ; 5-3=2 . \quad .5 \div 2=.25 .25$ per cent, or $1 / 4$ of the mixture, must be of the 5 per cent milk and 75 per cent of it must be of the 3 per cent milk. $100-25=75$ pounds of the 3 per cent milk to be used; 25 pounds of the 5 per cent milk to be used. 
10. The parallelogram method of standardization was devised by Professor R. A. Pearson, and is illustrated as follows:

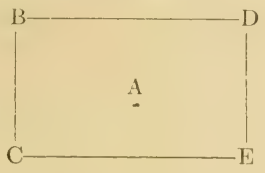

In the rectangle let $\mathrm{A}$ always represent the percentage of fat wanted in the standardized milk. Let $B$ represent the per "cent of fat in the milk or cream of the higher fat content. Let $\mathrm{C}$ represent the per cent of fat in the milk or cream of the lower fat content. The proportion $\mathrm{D}$ is secured by subtracting $\mathrm{C}$ from $\mathrm{A}$; and the proportion $\mathrm{E}$ is secured by subtracting $\mathrm{A}$ from B. D represents the proportion of B to be taken, and E represents the proportion of $\mathrm{C}$ to be taken.

These proportions give the parts of the milk or cream of the different percentages of fat which when added together in these proportions will give the desired percentage of fat in the standardized milk or cream. These proportions when added together and divided into the amount desired will give in pounds the value of each part. This multiplied by the number of parts found in each proportion will give the number of pounds of each to use. To illustrate:

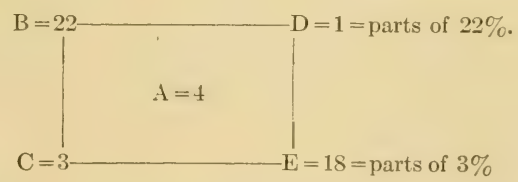

95 pounds of 4 per cent milk is desired. It is to be made from milk testing 3 per cent and cream testing 22 per cent.

$18+1=19$ parts. $95 \div 19=5 . \quad 5$ represents the value in pounds of one part or proportion. Then $5 \times 18=90$ pounds of 3 per cent to use. $5 \times 1=$ 5 pounds of 22 per cent to use.

11. Where milk is to be reduced by adding skimmilk.

By dividing the percentage of fat in the milk wanted by the percentage of fat in the milk on hand will give the percentage or the amount of the milk to be used, and the rest must be added as skimmilk. Thus:

300 pounds of 5 per cent milk is to be mixed with skimmilk to form 4 per cent milk. $(4 \div 5=.80$.) Then 300 pounds represents 80 per cent of the 


\section{DAIRY RULES (CONTINUED)}

mixture wanted, and the rest, or 20 per cent, equals the amount that must be added as skimmilk. 20 per cent of $300=75 . \quad 300+75=375$ pounds of the standardized milk.

12. Where milk is to be raised to a higher per cent of fat by adding milk or cream of a still higher fat content.

Subtract the percentage of fat in the milk on hand which contains the lower fat content from the percentage desired in the standardized product. Take the difference between the percentage of fat in the milk or eream of the higher fat content and the desired percentage of fat in the standardized milk. Divide the first result by the second, and the result represents the part of the milk or cream of the higher per cent fat to be used. Multiply this result by the pounds of milk which contains the lower per cent fat, and this will give the amount of the richer milk to add. This, added to the amount of the milk with the lower fat content, will give the total amount standardized. Thus:

300 pounds of 3 per cent milk is to be made to test 3.5 per cent by adding 5 per cent milk. (3.5 per cent -3 per cent $=.5$; and 5 per cent -3.5 per cent $=1.5) ; .5 \div 1.5=.331 / 3 ; 300 \times .331 / 3=100$. Use 100 pounds of 5 per cent milk with 300 pounds of 3 per cent milk, or a total of 400 pounds of 3.5 per cent standardized milk.

13. By dividing the per cent of fat in the standardized milk into the percentage of fat in the milk on hand and multiplying the result by the number of pounds of the milk on hand will give the number of pounds of the standardized milk which can be made from the milk on hand. If the quantity of the standardized milk is less than the amount on hand, then the difference must be taken out as skimmilk; if greater, it must be added as skimmilk. To illustrate:

300 pounds of 3.5 milk will make how many pounds of 4 per cent milk? $3.4 \div 4=.850 ; .850 \times 300=255$ pounds of 4 per cent milk which can be secured, or $300-255=45$ pounds of skimmilk to be removed.

14. When it is desired to determine the number of pounds of standardized milk a quantity of milk of a lesser per cent of fat will make.

Find the pounds of butterfat in the quantity of milk by multiplying the pounds of milk by the per cent (point fat off two places). Then by dividing this result by the pereentage fat desired in the standardized milk and multiplying the result by 100 will give the number of pounds of standardized milk. Thus:

300 pounds of 3.5 milk contains $(300 \times 3.5=10.5)$ pounds fat. This would make $(10.5 \div 4 \times 100=262.5)$ pounds of milk testing 4 per cent. 
Oвлест.-To determine the physical differences between milk, cream and skimmilk.

Apparatus.-Samples of milk, cream, and skimmilk, beakers, and microscopes.

Nоте то Ixstructons.-Slides of skimmilk, whole milk, and cream should be prepared previous to the class period, and adjusted in the microscope, as students in first taking up this work will not be familiar enough with the different apparatus to properly make up the slides.

Step 1. Study the differences found in the appearance of the sample of the milk, cream, and skimmilk.

Step 2. Study the field under the first microscope. Note the size, the shape, and the color of the fat globules.

Step 3. Study the field under the second microscope. Note the number of fat globules compared with those in the field of the first microscope. Note their size and shape.

Step 4. Study the field under the third microscope. Note the size and shape of the globules compared with those of the second microscope.

Step 5. Draw one of the fields in the space of this page. Write up the steps at the bottom of this page, explaining all the differences noted in the three fields. 


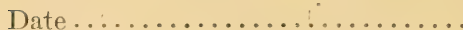

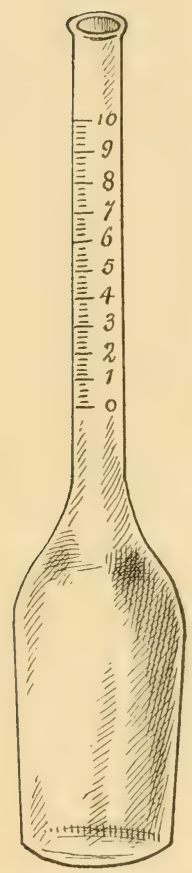

Whole milk bottle.

\section{EXERCISE 2.}

Овлест.-To determine the accuracy of the calibration of the glassware used for the Babcock test.

Apparatus.- Set of bottles used for test, and burette. Sheet of filter paper.

Step 1. Burette Method.-Fill the bottle to be tested to the zero mark with water. By means of a strip of filter paper remove any water adhering inside the neck above the zero mark. Measure into the bottle, from an accurate burette, 1 cc. of water. If the bottle is correct this should bring the water to the 5 per cent mark. Another cc. from the burette should bring the water to the 10 per cent mark.

In case of the cream bottles, if 9 gram bottles are used, $1 \mathrm{cc}$. of water will fill the bottle to the 10 per cent mark, or 5 cc. to 50 per cent mark.

Test all bottles by this method, recording all data.

Step 2. Accuracy of the Pipette.-Allow $17.6 \mathrm{cc}$. of water from the burette to run into a pipette, the bottom of which is closed with the finger. If correct the water will be at the 17.6 cc. mark.

Any glassware showing more than .2 per cent error should not be used. 
Data.

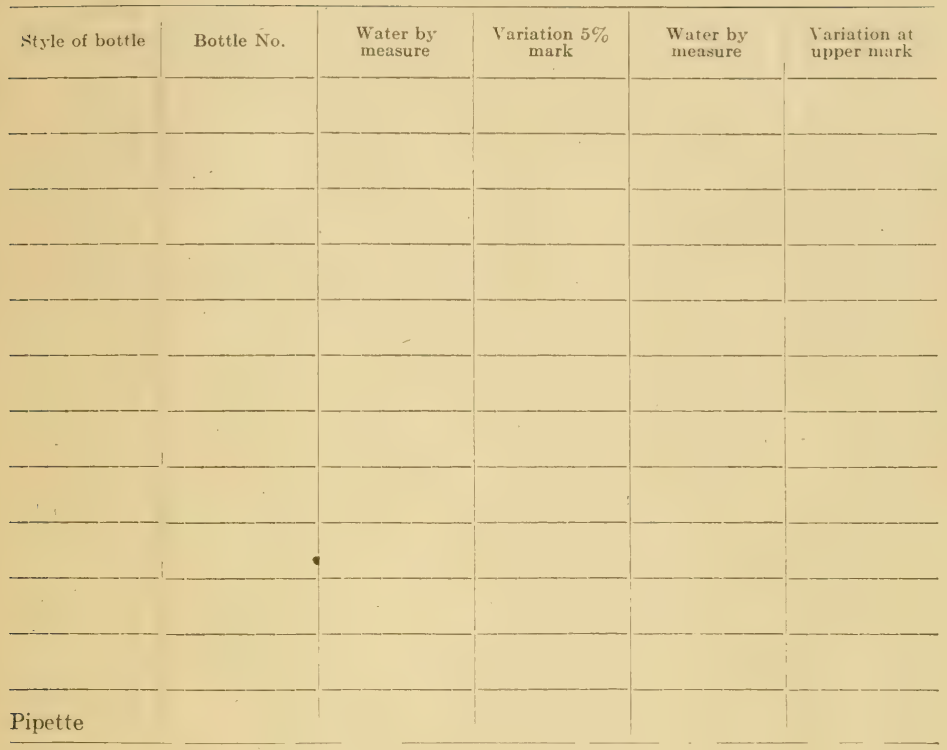


Grade ..........................

Date ...........................

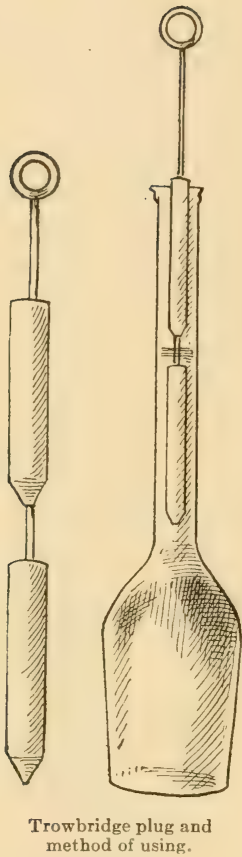

\section{EXERCISE 3.}

Овлест.-To determine the accuracy of the calibration of the glassware used for the Babcock test by the Trowbridge plug method; also a method for washing up glassware.

Apparatus.- Set of bottles used for the test, set of Trowbridge (or Nefus) plugs, sheet filter paper.

Part 1. Trowbridge Method.-Fill the bottle to the zero. With filter paper, dry the neck inside above the zero mark. Insert the plug until the water rises half way between the two sections. In a correct bottle the surface will be at 5 per cent. Lower the plug until the upper portion is $1 / 8$ inch below the surface. The water should be at the 10 per cent mark. Record all data.

Part 2. All glassware should be thoroughly washed and be always left clean at the end of each laboratory period. Take a dish pan of warm water and put in it about two tablespoonfuls of some good washing powder. Put the bottles in the suds thus formed and let the bottles fill about half full of the hot solution. Then take bottles in each hand and shake well. After they have been washed as well as possible in this manner use a small bottle brush to clean out the necks of the bottles. Take

them out of the water and rinse with clean warm water. Use this same method for all other glassware. This method if carefully used will always keep all glassware in the best possible condition. Care and attention should be given to always have all apparatus in the best possible shape. 
EXERCISE 3 (CONTINUED)

Data.

\begin{tabular}{l|l|l|l|l|l}
\hline Style of bottle & Bottle No. & Variation 5\% mark & Variation at upper mark \\
\hline & & & & & \\
\hline & & & & \\
\hline & & & & \\
\hline & & & \\
\hline & & & \\
\hline & & & \\
\hline
\end{tabular}


Grade........................

Date.

\title{
EXERCISE 4.
}

OвJEст.-To make a test of milk for butterfat, by the Babcock method. Apparatus.-Two whole milk bottles; a 17.6 ce. pipette; acid measure; acid; sample of whole milk; two sample bottles; hot water bath.

Step 1. Practice using the pipette with water until you can reasonably adjust the amount to be taken; $17.6 \mathrm{cc}$.

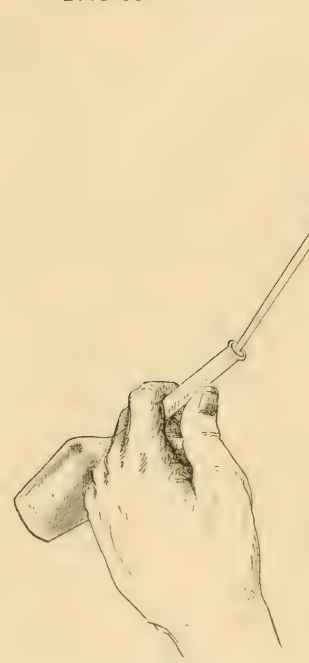

Correct position for filling bottles.

\author{
can
}

\author{
(2)
}

. 
Step 6. Agitate each bottle until the curd is all dissolved, by giving it a rotary motion as soon as acid is added.

Step 7. Put them into a centrifugal machine, whirl five minutes, fill to the neck with water about $130^{\circ} \mathrm{F}$, whirl two minutes, fill to about the 9 per cent mark, whirl one minute. Set in hot water bath $130^{\circ}-140^{\circ} \mathrm{F}$ with water around necks for 5 minutes, then read fat.

NotE.-Read the whole milk test from the top of the upper meniscus to the bottom of the lower meniscus.

Report.

\begin{tabular}{l|l|} 
Bottle No......... & B \\
\% fat........... &
\end{tabular}

1. Below give reasons for having the milk at $60^{\circ}$ to $70^{\circ}$.

2. Why is the milk poured from one vessel to another before sampling?

3. Explain the action of acid in the test.

4. Why should each sample of milk be tested in duplicate?

5. What is the color of the fat column?

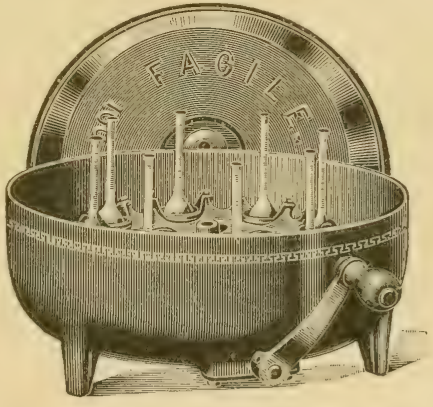

Eight-bottle hand tester. Farm size.

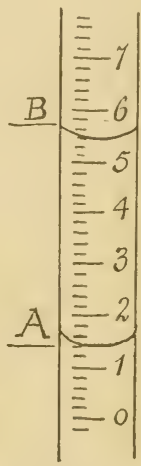

Correct method of taking reading on whole milk bottles. From the extremelower meniscus to the top of the upper meniscus. 
Grade.

Date. . .

\section{EXERCISE 5.}

Овлест.-To test whole milk for fat content by Babcock method.

Repeat Exercise 4. Test as many samples of milk as possible during the laboratory period.

\section{Report.}

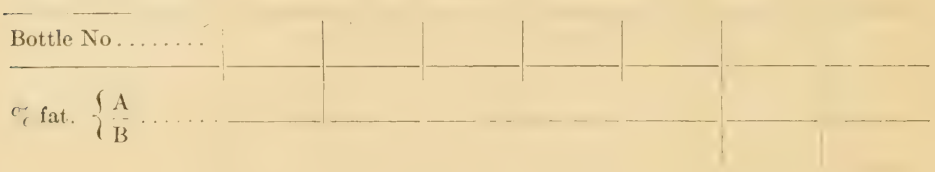

1. Try to account for any difference in tests between samples "A" and "B" in each case.

2. What would be the pounds of butterfat given by a cow giving 8000 pounds of milk per year with the fat test of your first sample?

3 . What would be its total value at 38 cents a pound?

4. Why is $17.6 \mathrm{cc}$. of milk used for the test?

5 . Why are the bottles set in water at $130^{\circ} \mathrm{F}$. before reading? 


\section{EXERCISE 6.}

OвJECT.-To test cream for fat content by Babcock method.

Apparatus. - Two cream bottles; acid measure; acid; 17.6 cc. pipette; sample of cream; two mixing beakers; scales; hot water bath.

Step 1. Mix sample of cream thoroughly by pouring from one beaker to another, care being taken not to churn it.

Step 2. Balance cream bottle A on scales and weigh into it 9 grams of cream. Duplicate in bottle B.

Step 3. Measure out about 9 cc. of water at $60^{\circ}$ to $70^{\circ}$ for each cream bottle. Add to each bottle.

Step 4. Measure out 17.5 cc. of acid for each bottle and complete test as for whole milk.

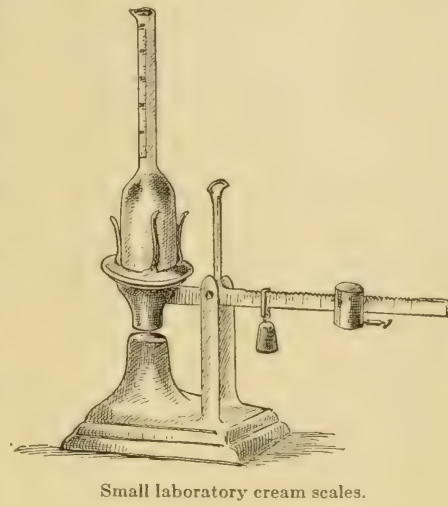

Note--Read cream test from bottom of fat column to bottom of top meniscus.

Report.

Bottle No

$\because$ fat $\left\{\begin{array}{l}A \\ B\end{array}\right.$

At the bottom of the page exrlain-

1. Why read cream columns different from milk.

2. Why cream is weighed out instead of being measured out, as is done with milk.

3. Why 9 cc. of water is added before the acid. 
Grade

Date .

\section{EXERCISE 7.}

Овлест.-To test cream for fat content by Babeock method.

Repeat Exercise 6. Run as many samples as possible, during laboratory period.

\section{Report.}

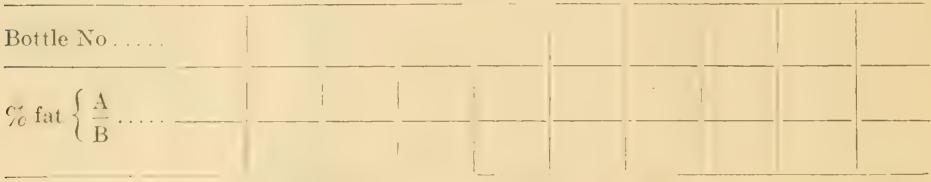
plain-

At the bottom of the page ex-

1. How many pounds of fat in 1875 pounds of cream with a test of the first sample?

2. What was the color of the fat in the column? Any variation?

3. What would hapyen if the acid were added before the water?

4. Why is 9 grams used for a sample.

5. When cream is weighed does it have to be at a temperature of from $60^{\circ}$ to $70^{\circ}$ ?

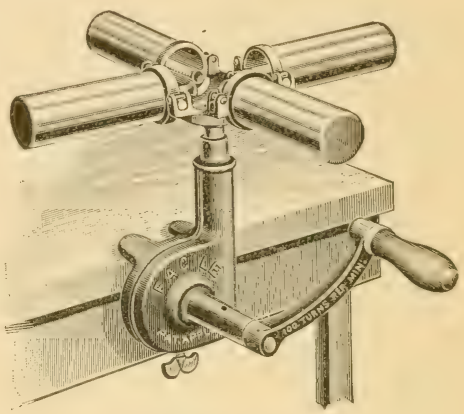

Small four-bottle tester. 


\section{EXERCISE - 8.}

OBJECT.-To determine the percentage of fat in skimmilk and whey.

Apparatus.-Samples of each; skimmilk and whey; skimmilk bottles; pipette; acid measure; mixing beakers; acid; hot water bath.

Step 1. Measure out 17.6 cc. first of skimmilk in each of two skimmilk bottles.

Proceed as for whole milk test except use a little in excess of $17.5 \mathrm{cc}$. of acid.

Step 2. Repeat test in the same manner using whey instead of skimmilk.

Report.
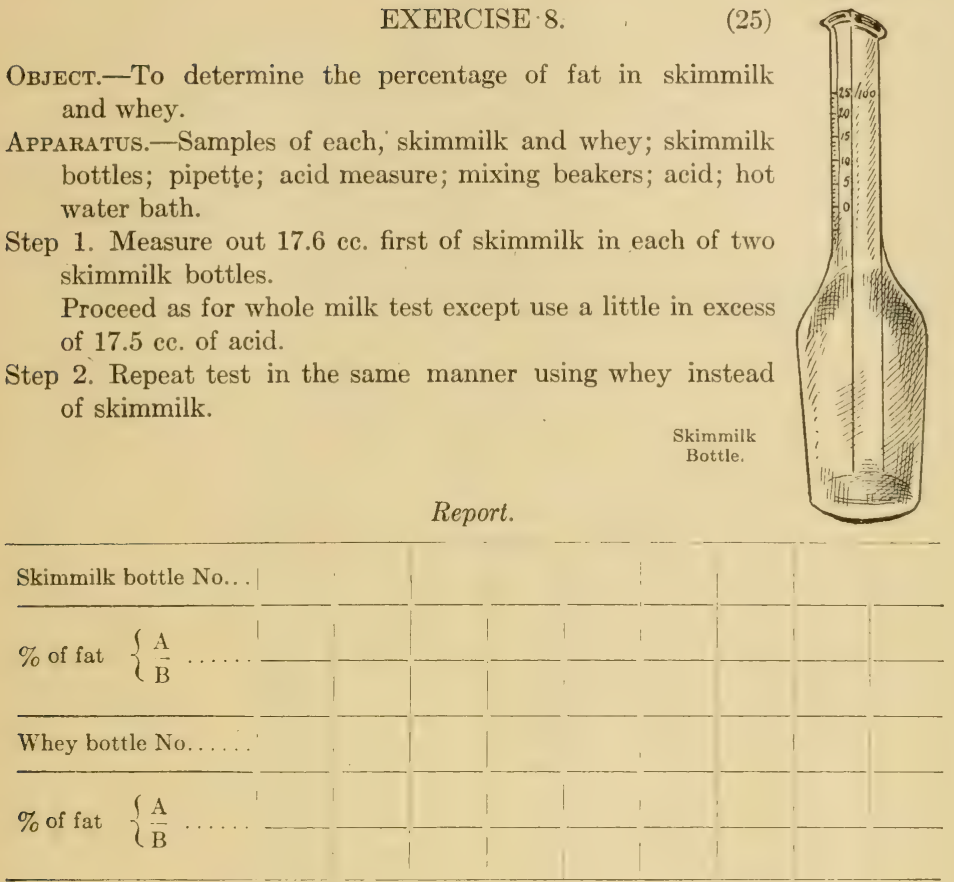

At the bottom of the page explain-

1. Why is a different bottle used for whole milk than skimmilk?

2. Why is a little more acid used than in the whole milk test?

3. How many pounds of fat in 1700 pounds of skimmilk with the above test? In 2500 pounds of whey with the above test? 
Овлест.-To determine the percentage of fat in buttermilk.

Apparatus.-Sample of buttermilk; two skimmilk bottles; two whole milk bottles; pipette; acid measure; mixing beakers, and acid.

Step 1. Measure out first $17.6 \mathrm{ce}$. of buttermilk in each of the skimmilk bottles; also make up duplicate tests of buttermilk in whole milk bottles, as buttermilk may be too high in fat content for skimmilk bottles.

Step 2. Complete the tests as before. Read the test which is the most accurately measured.

Report.

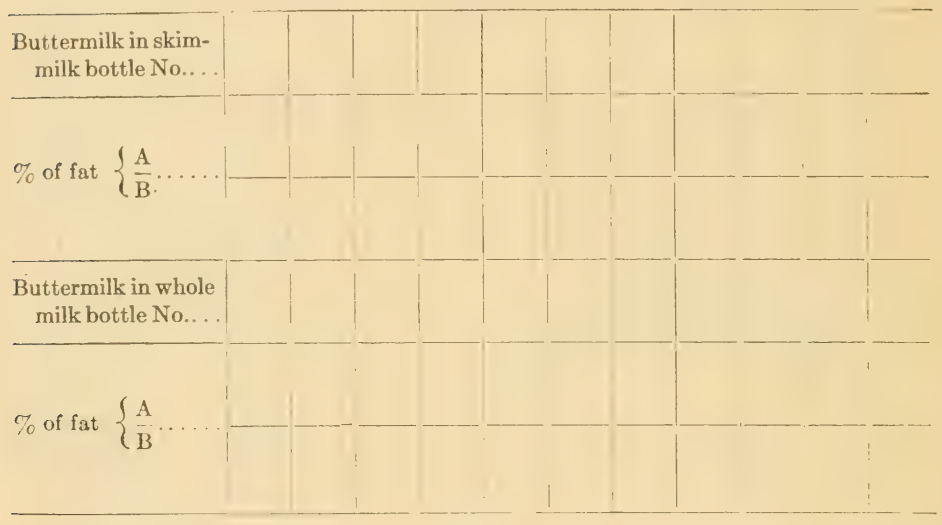

At the bottom of the page explain-

1. Why are two sets of bottles used for the buttermilk test?

2. Why is a little more acid used than with the whole milk test?

3. How many pounds of fat in $\mathbf{1 7 0 0}$ pounds of buttermilk with the above test? (Show operation.) 
Date

\section{EXERCISE 10.}

ОвJест.-To determine the specific gravity of milk.

Apparatus.-Lactometer; lactometer cylinder; thermometer, and sample of milk.

Step 1. Thoroughly mix sample of milk and regulate temperature between $60^{\circ}$ and $70^{\circ} \mathrm{F}$.

Step 2. Fill cylinder nearly full of sample of milk. Place lactometer in sample and observe exact reading on lactometer after it has become still. Caution.-Care is necessary to not let the lactometer drop in the cylinder, as the lactometer is very easily broken.

Step 3. Record exact temperature of sample and lactometer reading.

Step 4. Test sample by Babcock method for fat content.

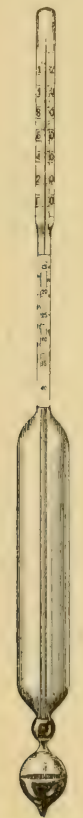

Lactometer.

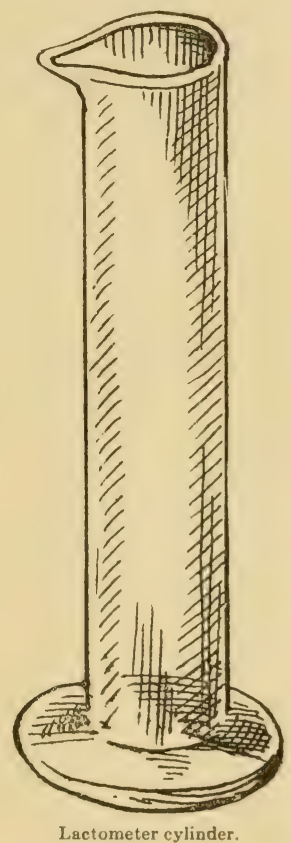

Lactometer cylinder. 


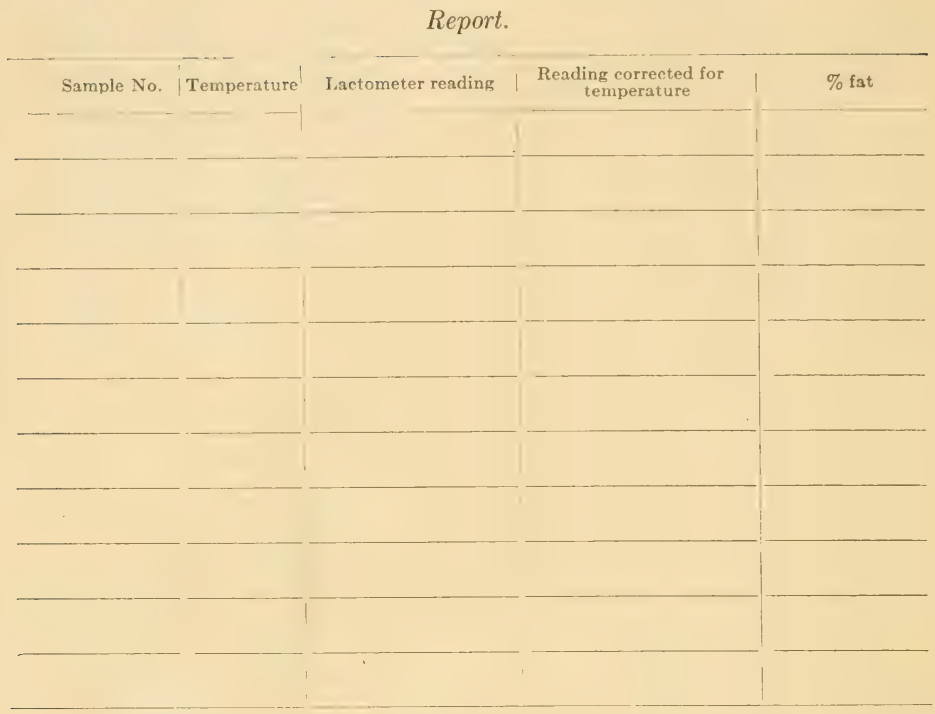

1. Calculate the solids not fat and the total solids from the above data. (For figuring total solids and solids not fat see rules $5, A$ and $\mathrm{B}$.)

2. What are solids not fat?

3. What is the specific gravity of normal cows' milk?

4. Why is it necessary to make the correction in the lactometer when the temperature is other than $60^{\circ}$ ?

5. When milk is heated, what is the effect on its specific gravity?

6. How does cooling milk affect the specific gravity? 
OBJECT.-To determine the total solids and the solids not fat in milk.

Apparatus.-Babcock test outfit; lactometer and equipment; a sample of whole milk.

Step 1. Regulate temperature of whole milk sample until near $60^{\circ} \mathrm{F}$. Pour into cylinder and carefully take lactometer reading.

Step 2. Make a Babcock test for fat. Record all data, and by rules $5, A$ and $B$ figure out the total solids and solids not fat for the sample. Repeat for a second sample.

Report.

\begin{tabular}{|c|c|c|c|c|}
\hline & $\begin{array}{l}\text { Lac. reading correct- } \\
\text { ed for temp. }\end{array}$ & $A^{\% \text { fat }}$ B & Solids not fat & Total solids \\
\hline Sample No. 1 ...... & & & & \\
\hline Sample No. 2 . & & & & \\
\hline
\end{tabular}

1. What would be the total solids in a sample having a lactometer reading of 32.6 at $68^{\circ} \mathrm{F}$. and a fat test of 3.8 per cent?

2. How many pounds of solids not fat in 400 pounds of this milk? 
Grade

Date

(30)

EXERCISE 12.

OBJECT.-To determine the specific gravity and adulteration of milk.

Apparatis.-Two samples adulterated with water; one normal sample; lactometer and cylinder; thermometer; test outfit; mixing beakers.

Step 1. Proceed as in Exercise 11.

Step 2. Record data, figure out solids not fat, whether samples are adulterated or not. If adulterated, nature and percentage of adulteration.

Report.

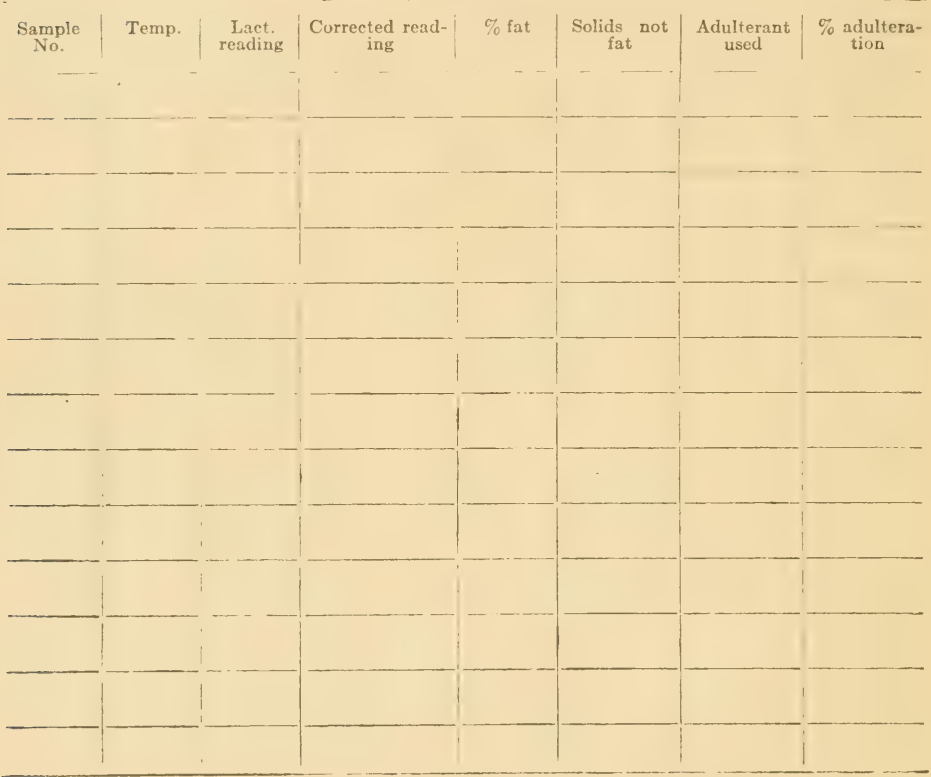


1. Calculate the solids not fat in a sample of milk testing 3.6 per cent fat, with a lactometer reading of 34 at $52^{\circ} \mathrm{F}$.

2. What are the solids not fat in a sample of milk testing 2.8 per cent fat, with a lactometer reading of 26 at $60^{\circ} \mathrm{F}$.?

3 . Is this sample adulterated?

4. If this sample has been adulterated, what has probably been used as an adulterant?

5. What makes you think this? 
Grade

Date

\section{EXERCISE 13}

OвJEст.-To determine the effect of not mixing a sample previous to testing. Apparatus.-Sample of milk that has stood for an hour or two without being stirred; the Babcock test outfit.

Step 1. Without disturbing the sample of milk on the desk, draw two samples from the top.

Step 2. Draw two samples from the bottom.

Step 3. Mix the milk thoroughly by pouring; take two samples.

Step 4. Add proper amount of acid to each, mix and complete the tests.

Report.

Bottle No.....

1. Explain below what would be the losses to a creamery receiving 45,000 pounds of milk daily if the above careless methods were used in testing the samples, supposing the sample was taken from the top.

2. What loss to patron if sample is taken from bottom?

3 . What would be the percentage of error in the above tests? 
Овлест.-To determine effect of temperature when reading the fat test.

Apparatus.-Sample of cream; whole milk; skimmilk; Babcock test outfit. Step 1. Measure out two bottles of whole milk, two of skimmilk. Put 9 grams of cream into each of two cream bottles.

Step 2. Add proper amounts of acid, mix and complete the tests.

Step 3. Take reading as soon as whirling is complete.

Step 4. Temper the water bath to $200^{\circ} \mathrm{F}$. Insert the bottles so the water comes near the top. After being inserted five minutes, read.

Step 5. Lower the water to $150^{\circ} \mathrm{F}$., after five minutes read.

Step 6. Lower to $130^{\circ} \mathrm{F}$. and, after five minutes, read.

Step 7. Lower the water to $90^{\circ} \mathrm{F}$. and, after five minutes, read.

Report.

\begin{tabular}{|c|c|c|c|c|c|c|}
\hline & \multicolumn{2}{|c|}{ Whole'milk } & \multicolumn{2}{|c|}{ Skimmilk } & \multicolumn{2}{|c|}{ Cream } \\
\hline 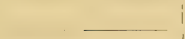 & A & B & A & B & A & B \\
\hline \multicolumn{7}{|l|}{ Bottle No..... } \\
\hline \multicolumn{7}{|l|}{$\begin{array}{l}\text { First reading } \% \\
\text { fat........... }\end{array}$} \\
\hline \multicolumn{7}{|l|}{$200^{\circ} \tau_{0}$ fat $\ldots .}$. \\
\hline \multicolumn{7}{|l|}{$150^{\circ} \%$ fat..... } \\
\hline $130^{\circ} \%$ fat...... & & & & & & \\
\hline $90^{\circ} \%$ fat... & & & & & & \\
\hline
\end{tabular}

1. Which is the proper reading and why?

2. What would be the loss to a ereamery taking in 30,000 pounds of cream if the test was read, as in step 4 , at $200^{\circ}$ ?

3. What loss to patron if read, as in step 7 , at $90^{\circ}$ ?

4. Give variation in the color of the fat at the different stages. 
Овлест.-To determine the effect of speed of the tester upon the test. Apparatus.-Samples of whole milk; skimmilk; Babcock test outfit. Step 1. Prepare three test samples of whole milk.

Note- - In this exercise have all conditions alike except speed.

Step 2. Prepare three test samples of skimmilk using skimmilk bottles.

Step 3. To the skinmilk add a little more than a full mearure of acid. Mix as usual.

Step 4. Run one bottle of whole milk and one of skimmilk at half speed; one of each at proper speed; one of each at high speed.

Report.

\begin{tabular}{ll|l|l}
\hline At half speed $\ldots \ldots \ldots \ldots$ & Speed & Whole milk \% fat & Skimmilk \% fat \\
\hline At proper speed . . . . . . & \\
\hline At high speed..........
\end{tabular}

At the bottom of the page explain-

1. The effects on the color of the fat.

2. Other effects of insufficient speed.

3. Other effects of too much speed. 
Grade

Date

\section{EXERCISE 16.}

Овлест.-To determine the effect of varying amounts of acid in the Babcock test.

Apparatus.-Sample of whole milk; Babcock outfit.

Step. 1. To one sample add the regular measure of acid.

Step 2. To another add half the regular amount of acid, $8.8 \mathrm{cc}$.

Step 3. To another add 1 1/2 measures of acid, $26.3 \mathrm{cc}$.

Step 4. Mix and test in the usual way.

Report.

\begin{tabular}{l}
\hline Regular measure \\
Bottle No . . Half measure
\end{tabular}$\ldots \ldots \ldots$

1. What is the effect of insufficient acid?

2. Of too much acid?

3. Write a full description of clearness, color and correctness. 
Grade......................

Date.......................

OвJест.-To determine the effect of temperature of milk and incomplete mixing of acid and milk.

Apparatus.- Sample of whole milk; Babcock test outfit.

Step 1. Measure out two samples, add acid at once and mix thoroughly. (usual method).

Step 2. Measure out two samples, place in water bath at $130^{\circ}$ for ten minutes; then add acid and rotate to dissolve curd.

Step 3. Measure out two samples, add acid but allow same to stand ten minutes before dissolving curd.

Step 4. Complete all tests.

Report.

Bottle $\mathrm{N}_{0} \ldots \ldots+\frac{1}{1}$

Explain below-

1. The effect of having the sample too hot before adding the acid.

2. The effects of allowing the sample to stand with the acid on it before mixing.

3. Give the different colors of fat in the tests above and give reasons for these changes. 
Grade

Date ..........................

EXERCISE 18.

OBJECT.-To determine the effect of measuring cream as compared with weighing it.

Apparatus.-Sample of cream; Babcock outfit; 2 9-gram and 4 18-gram cream bottles.

Step 1. Measure into each of two 18-gram bottles 17.6 cc. of cream.

Step 2. Add $17.5 \mathrm{cc}$. of acid, rotate well and allow to stand until mixture turns black, then add hot water up to the neck of the bottle.

Step 3. Weigh out 18 grams of cream into each of two 18-gram bottles. Add acid and water as in step 2.

Step 4 . Weigh into each of two 9-gram bottles 9 grams of cream and test in the usual manner.

Report.

\begin{tabular}{|c|c|c|c|c|c|c|}
\hline \multirow{2}{*}{ - } & \multicolumn{2}{|c|}{$17.6 \mathrm{ce}$. cream } & \multicolumn{2}{|c|}{ Is grams cream } & \multicolumn{2}{|c|}{9 grams cream } \\
\hline & A & B & A & B & A & B \\
\hline \multicolumn{7}{|l|}{ Bottle No...... } \\
\hline$\%$ fat. & & & & & & \\
\hline
\end{tabular}

1. Which test should be the correct one?

2. Give the advantages and disadvantages of weighing out cream for a test.

3. With how many pounds of fat would a cream patron be over-credited if he delivered 467 pounds of cream and was allowed the highest test?

4. How much would he be short if paid by the lowest test, butter being worth 30 cents per pound, overrun being 14 per cent? 
Grade

Date

(38)

EXERCISE 19.

Овлест.-To determine the effect of adding water before whirling in the 9-gram cream test.

Apparatus.-Sample of cream; Babcock test outfit.

Step 1. Weigh into each of two 18-gram bottles 18 grams of cream.

Step 2. Weigh into each of two 9 -gram bottles 9 grams of cream.

Step 3. Add the proper amount of acid to each lot. After standing a few minutes add hot water to one half of each lot.

Step 4. Mix and finish the tests.

Report.

\begin{tabular}{|c|c|c|c|c|c|c|c|c|}
\hline & \multicolumn{2}{|c|}{$\begin{array}{l}18 \text { grams } \\
\text { no water }\end{array}$} & \multicolumn{2}{|c|}{$\begin{array}{c}18 \text { grams } \\
\text { with water }\end{array}$} & \multicolumn{2}{|c|}{$\begin{array}{l}9 \text { grams. } \\
\text { no water }\end{array}$} & \multicolumn{2}{|c|}{$\begin{array}{c}9 \text { grams } \\
\text { with water }\end{array}$} \\
\hline & A & $B$ & A & B & A & B & A & B \\
\hline \multicolumn{9}{|c|}{ Bottle No. $\mid$} \\
\hline$\widetilde{T}_{0}$ fat. & & & & & & & & \\
\hline
\end{tabular}

Write a full description of the variations in the above tests with reasons for (a) color, (b) clearness, and (c) correctness of the fat test. 
Grade......$\ldots \ldots \ldots \ldots \ldots$

Date .....................

EXERCISE 20.

Овлест.-To test butter for percentage of fat.

Apparatus.-Sample of butter; Babcock test outfit.

Step 1. Preparing sample.-Put a fair sample into a tightly stoppered bottle. Put the bottle into water at $95^{\circ} \mathrm{F}$. and shake thoroughly until melted. Then put the bottle into cold water and shake well until butter becomes of a thick, creamy consistency. From this sample small portions may be taken for testing.

Step 2. Testing.-Weigh 9 grams of butter into each of two bottles graduated to 50 per cent, add $10 \mathrm{cc}$. of hot water, and about $8.5 \mathrm{cc}$. of acid. Mix until all the curd is dissolved. Add hot water to bring the fat into the neck of the bottle. Whirl in a centrifuge for five minutes and read. The reading multiplied by 2 will be the correct test.

Report.

\begin{tabular}{|c|c|c|c|c|c|c|c|c|c|c|}
\hline \multirow[b]{2}{*}{ Bottle No. } & A & B & A & B & A & B & A & B & A & B \\
\hline & & & & & & & & & & \\
\hline$\%$ fat. & & & & & & & & & & \\
\hline
\end{tabular}

1. If butter contains 80 per cent fat what should be the pereentage of overrun?

2. What is the average composition of butter?

3. What is the percentage of butterfat allowed by law? 
Grade

Date.

(40)

EXERCISE 21.

()BJECT.-To note the acidity of milk products, and to compare the method of determining the acidity.

Apparatus.-Sample of milk; cream; cheese; skimmilk; buttermilk; Farrington's, Mamn's and Van Norman's apparatus; solution for acidity tests.

Step 1. Follow the printed directions for the particular test being used. (See rule 6.)

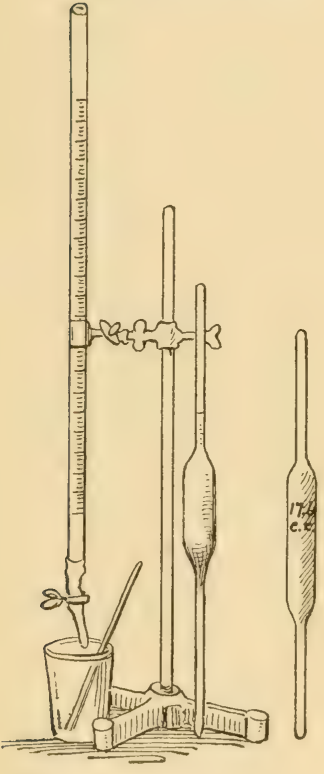

Apparatus for acid test.

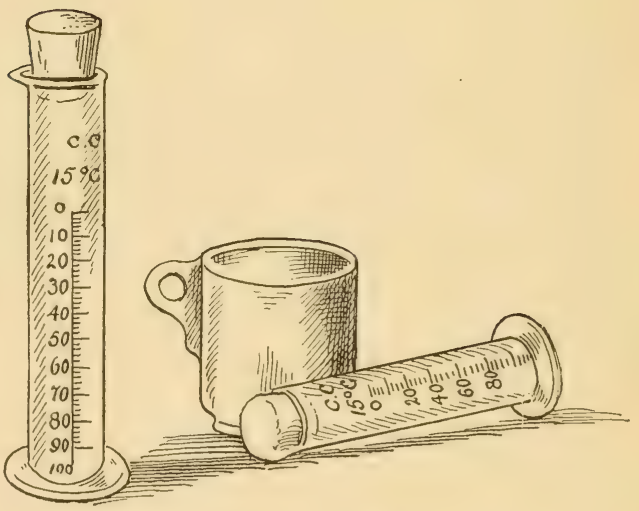

Farrington's acid test apparatus. 


\section{Report.}

\begin{tabular}{|c|c|c|c|c|c|}
\hline & \multirow{2}{*}{ Sample } & \multicolumn{2}{|c|}{ Percentage acidity } & \multirow{2}{*}{$\begin{array}{l}\text { Mann's } \\
\text { Degrees }\end{array}$} & \multirow{2}{*}{$\begin{array}{l}\text { Calculate } \\
\text { by Mann's }\end{array}$} \\
\hline & & Farrington's & Van Norman's & & \\
\hline \multicolumn{6}{|l|}{ Milk A....... } \\
\hline \multicolumn{6}{|l|}{ Milk B. . } \\
\hline \multicolumn{6}{|l|}{ Cream A. } \\
\hline \multicolumn{6}{|l|}{ Cream B. } \\
\hline \multicolumn{6}{|l|}{ Skimmilk A.... } \\
\hline \multicolumn{6}{|l|}{ Skimmilk B...' } \\
\hline \multicolumn{6}{|l|}{ Buttermilk A. } \\
\hline \multicolumn{6}{|l|}{ Buttermilk B. . } \\
\hline \multicolumn{6}{|l|}{ Cheese A..... } \\
\hline Cheese B..... & & & & & \\
\hline
\end{tabular}

Write the advantages and disadvantages of each test. 
Date

\section{EXERCISE 22}

Овлест.-To standardize milk and cream.

Apparatus.-Sample of milk and cream; Babcock test outfit; sample bottles; cream scales.

Step 1. Run test for fat on both cream and milk samples.

Step 2. Standardize 100 grams of 4 per cent milk from the tested cream and whole milk samples.

Step 3. Standardize 100 grams of 20 per cent cream from the tested whole milk and cream samples.

Step 4. Run fat tests on all standardized samples and record data.

Report.

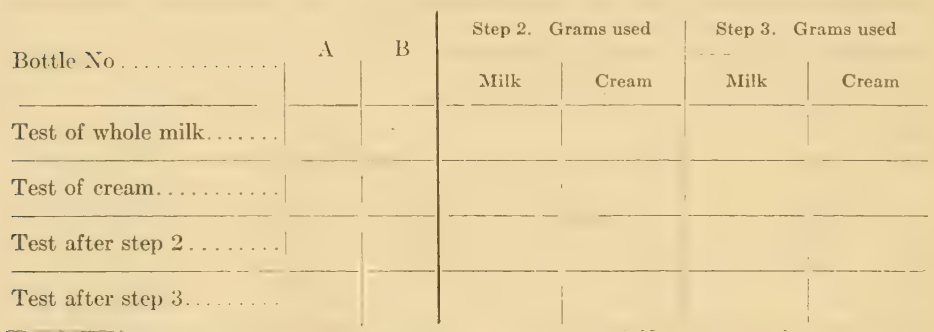

Work out the following problems-

1. One thousand pounds of 3.6 per cent milk is to be raised to 4 per cent milk; how much skimmilk must be taken out?

2. How much 30 per cent cream and skimmilk must be used to make up 1000 pounds of 25 per cent cream?

3. How much 36 per cent eream and 3.6 per cent milk must be used to make up 800 pounds of 25 per cent cream?

4. How many pounds of 40 per cent cream and 4 per cent milk must be used to make up 90 pounds of 20 per cent cream? 
Grade

Date.

EXERCISE 23.

OвJECT.-To prepare a commercial starter.

Apparatus. - A pint bottle, sterilized; a sample of commercial starter; a sterilized graduated cylinder; a sample of pasteurized skimmilk; a thermometer.

Step 1. Measure out $25 \mathrm{cc}$. of the commercial starter into a sterilized pint bottle. Add to it $225 \mathrm{cc}$. of pasteurized skimmilk at a temperature of $80^{\circ} \mathrm{F}$.

Step 2. Place cover on bottle and set away in starter box at a temperature of $70^{\circ} \mathrm{F}$. for 24 hours. Hold at this temperature until all changes have been noted.

Step 3. Record all the changes which a starter undergoes from the time it is made up until observations are complete.

1. Write a full description of a starter and all the changes which take place in its manufacture.

2. Explain as fully as possible the reasons for each change.

3. Give briefly the advantages of using a starter. 
Date

\section{EXERCISE 24.}

OBJECT.-To learn the correct use of milk coolers.

APParatus.-Quantity of water or milk; milk cooler; supply of milk cans; thermometers.

Step 1. Weigh out 100 pounds of the milk or water and have the temperature about that of milk when taken from the barn, $90^{\circ}$. Place in the cooler vat.

Step 2. Arrange the cold water inflow to give full flow, take the temperature of inflow, of outflow, and length of time to cool the milk to $50^{\circ}$ and the amount of water needed. Record data below.

Step 3. Same as step 1 and 2 except have water passing through the cooler with only half pressure. Record data.

Step 4. Same as step 1 and 2, only determine the length of time and amount of water necessary to cool to within 3 degrees of the temperature of the water. Take temperature of inflow and outflow in all cases.

\begin{tabular}{|c|c|c|c|c|c|c|}
\hline & $\begin{array}{l}\text { Temp. } \\
\text { milk }\end{array}$ & $\begin{array}{l}\text { Temp. } \\
\text { inflow }\end{array}$ & $\begin{array}{l}\text { Temp. } \\
\text { outflow }\end{array}$ & Time & $\underset{\text { required }}{\text { Amt. water }}$ & $\begin{array}{c}\text { Temp. when } \\
\text { cooled }\end{array}$ \\
\hline Step $2 \ldots \ldots$ & & & & & & \\
\hline Step $3 \ldots$. . & & & & & & \\
\hline Step $4 \ldots \ldots$ & & & & & & \\
\hline
\end{tabular}


Grade

Date .

EXERCISE 25.

Овлест.-To make a comparative study of cream separators.

Apparatus.--Separators in separator room.

Steps. Study several separators and fill the record columns correctly.

\section{Record.}

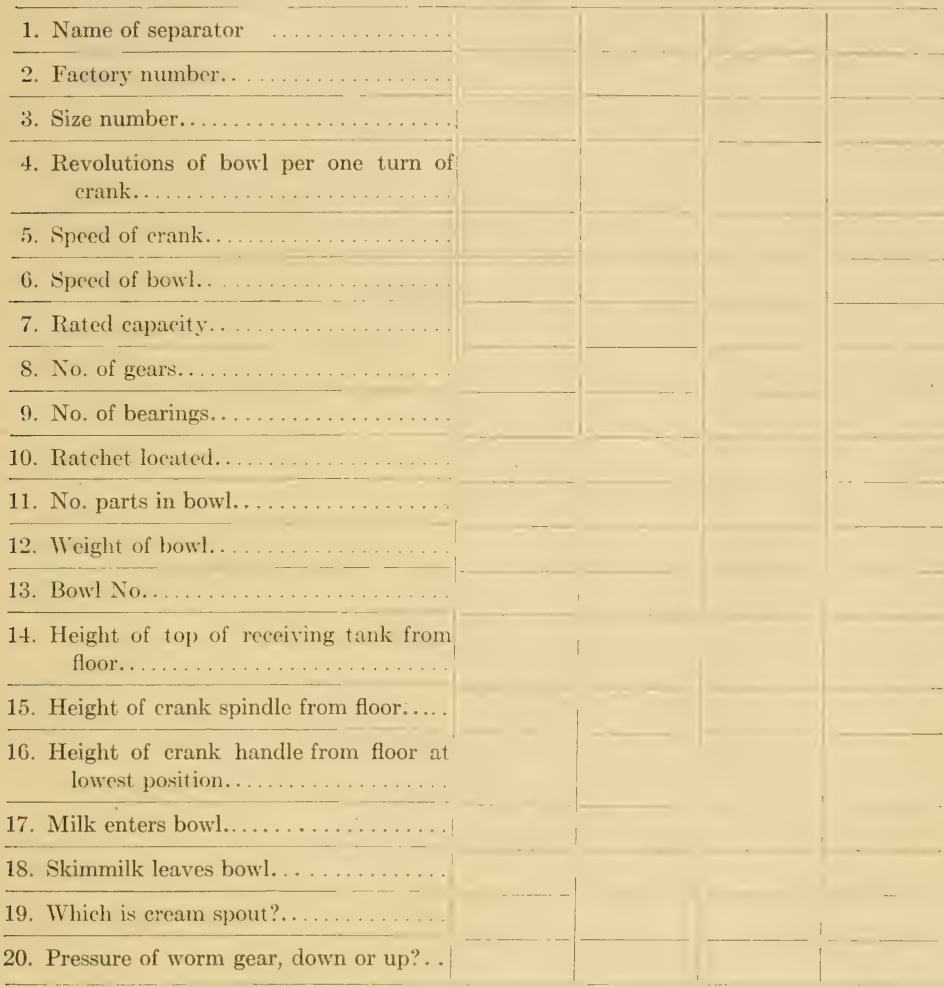

Write a criticism of each machine studiec - give its special advantages and its disadvantages. 
Date .

EXERCISE 26.

OвJест.-Comparative study of separators.

Apparatus.--Separators in separator room.

Procedure.-Carefully remove the neck bearing which is located in the upper seating for the bowl. Study the character of the bearing with regard to the points indicated below. When through, carefully replace and adjust the bearings before leaving the machine. Follow the same instructions for the bottom bearing which is located at the lower seating of the spindle.

Report.

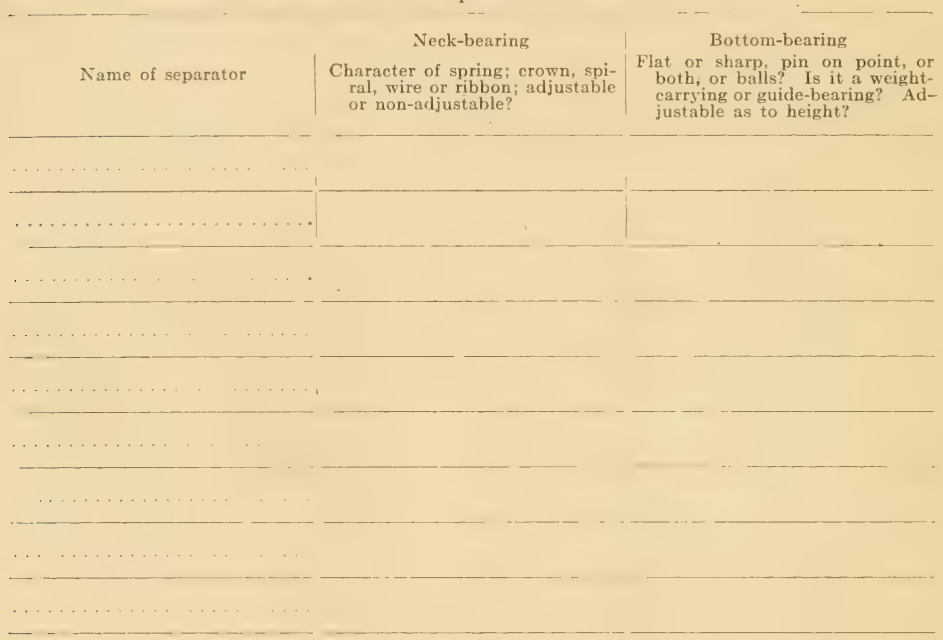

At the bottom of the page make criticism as to ease of removing and replacing the bearings, of each of the machines studied. 
Овлест.-To determine the capacity of separators.

Apparatus.-Two large dippers; 2 fourteen quart pails; a quantity of milk. (Two or more students may work together.)

Step 1. See that the milk is at the right temperature, $90^{\circ}$ to $98^{\circ} \mathrm{F}$, and that there is a sufficient amount to maintain a full flow during the experimental run. Start separating, and catch the first eream and skimmilk in dippers. When the milk is running a normal flow, take the dippers away and let the skimmilk and cream run into the regular pails for exactly one minute. Take them away and let the rest of the milk run into the dippers. Weigh up the amount of skimmilk and cream which was caught in the one-minute experimental run. Compute the capacity per hour. Flush bowl with warm rinse water. Save samples of skimmilk and cream.

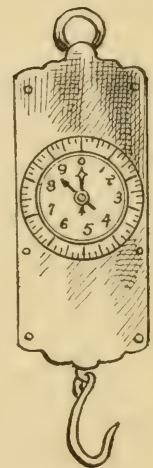

Spring balance for weighing milk.

Report.

1. Name of separator.

2. Nize

3. Rated capacity per hour

4. Note speed of handle three times.

5. Temperature of milk at start;.... at finish

6. Pounds of skimmilk, .......... 1 min.; 1 hour

7. Pounds of cream, $1 \mathrm{~min}$; 1 hour

8. Pounds of skimmilk and cream, ... $1 \mathrm{~min}$;

1 hour.

Below show how long it would take each day to separate the milk from thirty cows, each giving 35 pounds daily, with a machine of a capacity of the above machines. 
Gracle

Date

(48) EXERCISE 28.

OвJECT.-To adjust height of bowl and position of cream screw.

Apparatus.-Separators in separator room; quantity of whole milk.

Step 1. Name of separator.

Step 2. See that height of bowl is such as to deliver skimmilk and cream into their respective covers without touching them. Before making any adjustment, study direction sheet for this machine thoroughly.

Step 3. With sufficient milk (or water) in supply can to maintain full flow, separate at least one gallon, shut off supply, weigh and compute what proportion the cream is of the total amount separated.

Step 4. Adjust cream screw to make the amount of cream between 12 and 14 per cent of the total separated.

Step 5. If already correct, adjust so as to make a change of between 4 and 6 per cent.

Report.

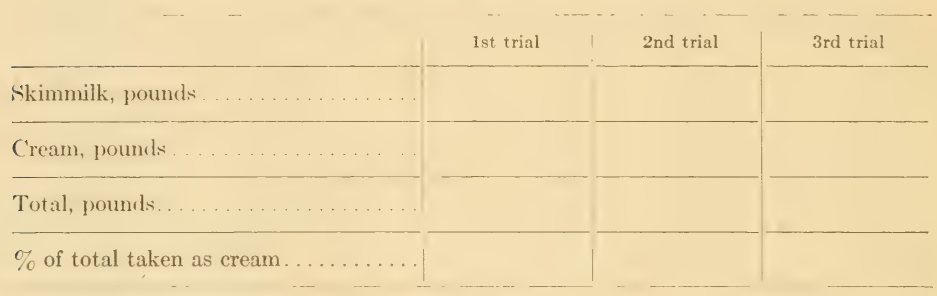

Explain below-

1. How much change was made in the cream screw?

2. How does the cream'screw affect the amount of cream?

3. How does it affect the amount of fat?

4. When water is separated, would the amount of water leaving the cream spout be the same as the amount of cream when milk is separated?

5. Give reason for your answer. 
OвJEct.-To determine the effect of speed variations on the proportion 'of cream, richness of cream, and on the loss of fat in skimmilk.

Apparatus.-Separators in separator room; quantity of whole milk.

Step 1. Have milk at $90^{\circ}$ to $98^{\circ} \mathrm{F}$.

Step 2. Separate half the milk at regular speed.

Step 3. Separate remaining half with speed reduced one-third.

Step 4 . Save sample of whole milk; also samples of cream and skimmilk from both two and three.

Report.

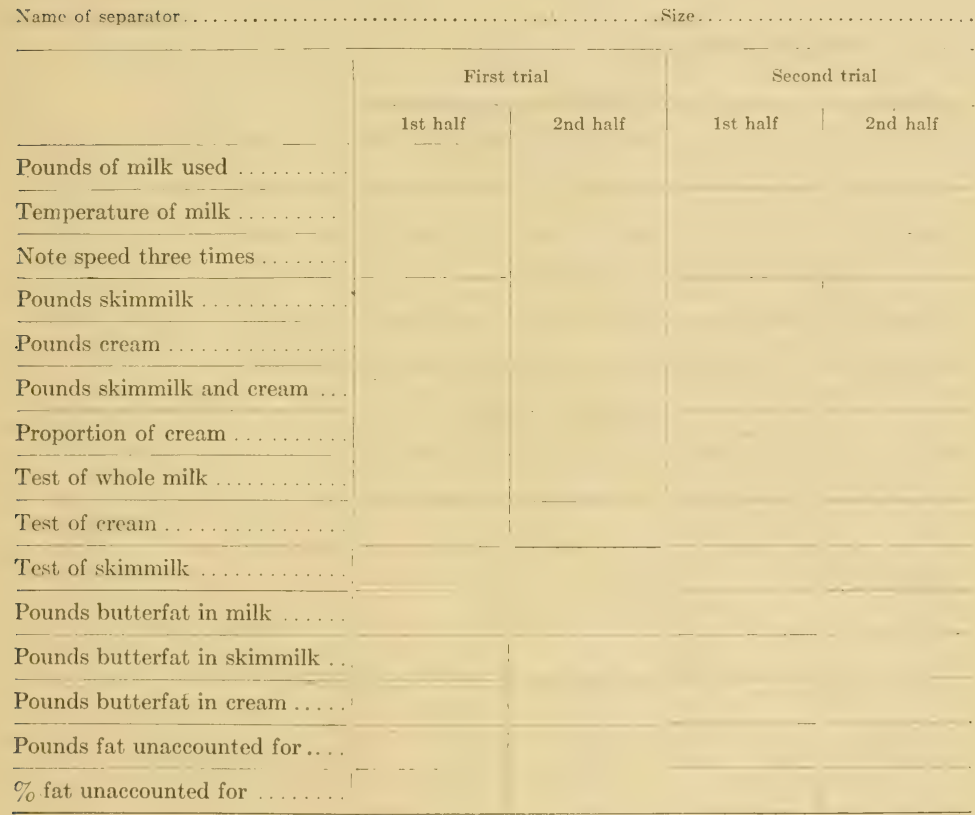

Write the reasons and effects of the variations that you have found in this exercise. 
Овлест.-To determine the influence of the change of inflow on the proportion and richness of cream, and the loss of fat in the skimmilk. Apparatus.-Separators in separator room; quantity of whole milk.

Step 1. Separate half the milk with faucet wide open and speed uniform.

Step 2. Separate the other half, starting with faucet wide open, then close till cream becomes noticeably thicker.

Note.-Maintain correct and uniform speed. Save samples and test.

Report.

Niame of separator. Size

\begin{tabular}{|c|c|c|c|c|}
\hline & \multicolumn{2}{|c|}{ First trial } & \multicolumn{2}{|c|}{ Second trial } \\
\hline & 1st half & 2nd half & 1st half & 2nd half \\
\hline \multicolumn{5}{|l|}{ Pounds of milk used } \\
\hline Temperature of milk ......... & & & & \\
\hline Note speed three times ........ & & & & \\
\hline \multicolumn{5}{|l|}{ Pounds skimmilk } \\
\hline \multicolumn{5}{|l|}{ Pounds cream } \\
\hline \multicolumn{5}{|l|}{ Pounds skimmilk and eream } \\
\hline \multicolumn{5}{|l|}{ Proportion of cream } \\
\hline \multicolumn{5}{|l|}{ Test of whole milk ............ } \\
\hline \multicolumn{5}{|l|}{ Test of cream } \\
\hline \multicolumn{5}{|l|}{ Test of skimmilk } \\
\hline \multicolumn{5}{|l|}{ Pounds butterfat in milk } \\
\hline \multicolumn{5}{|l|}{ Pounds butterfat in skimmilk } \\
\hline \multicolumn{5}{|l|}{ Pounds butterfat in cream ..... } \\
\hline Pounds fat unaccounted for .... & & & & \\
\hline$\%$ fat unaccounted for & & & & \\
\hline
\end{tabular}

Write the reasons and effects of the variations that you have found in this exercise. 
Овлест.-To determine the effect of variations in temperature of milk and proportion and richness of cream and loss of fat.

ApParatus:-Separator in separator room; quantity of whole milk.

Step 1. Separate half the milk at about $90^{\circ} \mathrm{F}$.

Step 2. Separate half the milk at about $50^{\circ} \mathrm{F}$.

Note.-Maintain correct and uniform speed. Save samples and test.

Report.

Name of separator. Size.

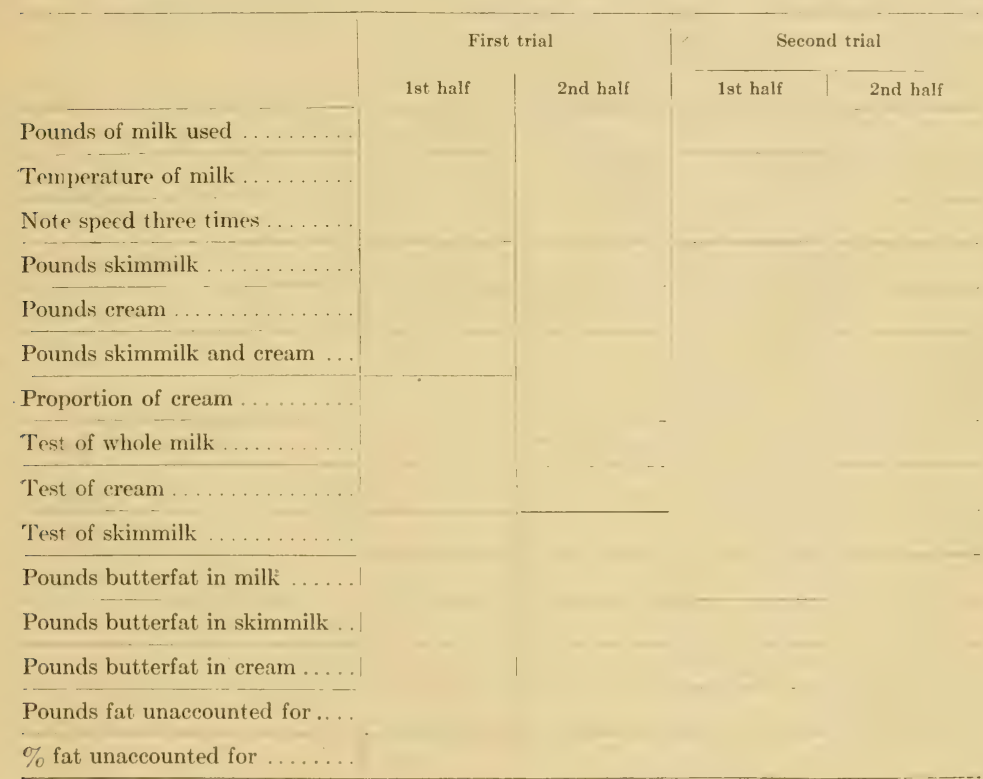

Write the reasons and effects of the variations that you have found in this exercise. 
Grade $\ldots \ldots \ldots \ldots \ldots \ldots \ldots$

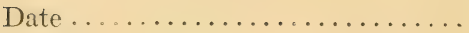

\section{EXERCISE 32.}

Овлест.-To churn butter from ripened cream (first churning exercise). Apparatus.-Churn; cream; scales; thermometer; pails; salt; color; etc. (Two or more students may work together in all churning exercises.)

Note.-Students going into the laboratory should first note the work to be done, which will be found on the slip on the bulletin board or on the blackboard.

General Instructions for Churning.-The principle of churning is the proper agitation of the cream that the butterfat which is in it is properly and thoroughly separated out.

Before churning, the cream should be properly ripened. That is, it should have been held at the proper temperature that the right amount of acidity may have developed in it.

The cream should have an acidity of from .3 to .5 per cent and be held at the temperature required for churning at least two hours before churning. The churning temperature will necessarily vary in the different seasons, but should run about $52-54$ in the summer and 54-58 in the winter.

The churn should be thoroughly scalded out to remove bad odors or taints and then cooled down with cold water. The cream should then be weighed and placed in the churn . and the churning process staried.

If a barrel churn, churn until the butter begins to break in small granules about the size of a grain of corn. Here the churning should stop. It should take not over 30 minutes to reach this stage if the cream was properly handled before starting to churn. If it takes less than 15 minutes it may mean that the churning temperature was too high.

Draw off the buttermilk through a sieve that the small particles of butter may not be lost. Take the temperature of the buttermilk. Pour over the butter, in the churn, about the same amount of water as cream used in the churning and from $4^{\circ}$ to $10^{\circ}$ cooler than the buttermilk. Rinse the butter in this water for about 15 to 20 revolutions of the churn. Draw off the water, and take the butter out on the working board and salt, using about one ounce of salt to the pound of butter. The salting may be done in the churn if it has a worker.

After salting, allow the salt to dissolve, then work the butter until the salt is in all parts and the buttermilk is out. Print and wrap in clean parchment paper.

Wash and seald all utensils and leave hot to dry.

student A. Weigh out the cream for chuming; get the temperature right, add butter-color if necessary, place cream in churn; make all necessary observations, record data; scald the butterworker and other woodenware and then chill thoroughly with cold water; get the necessary rinse water and have it at the right temperature. Weigh the salt and have things ready when churning is done. Draw off buttermilk, rinse butter, place butter on worker, salt, work and print. Finish recording data. (Record all data on the following page.)

Student B. Seald the churn with hot water and then chill thoroughly with cold water. Run the churn, take samples of buttermilk and wash up the churn. In washing up the churn rinse with luke-warm water and then wash thoroughly with scalding water and washing powder and 
scald with clear water. Use brush on the outside of the churn. Leave the churn hot. Wrap the butter, wash the butterworker, other woodenware, and pails in the same manner as the churn was washed. See that the floor is clean and dry and that each piece of apparatus is clean and in its place. Unclean or misplaced apparatus will count heavily against good butter making.

\section{CHURNING RECORD.-Churning No.............}

This blank should be neatly and accurately filled out when the product is finished.

Condition of cream. Pounds cream

Total pounds of fat

Temperature at which cream was ripened

Time to ripen

Length of time held at churning temperature.

$\%$ of fat in cream when churned

Kind and size of churn used.

Approximate fullness of churn

Temperature churned.

Time to churn.

Amount of color used.

Size of granules when churning stops .

Temperature of buttermilk. Test

Amount of wash water.

Temperature of wash water

Amount of salt used.

Brine or dry salted.

Butter from churn hard or soft

Pounds of butter.

Pounds of overrun

$\%$ overrun

Work and observations by . .

Assisted by

Make special notes regarding this churning operation. 
OBJEct.-To churn and make a good grade of butter from well ripened cream. (Second churning exercise.)

Apparatus.-The same as for Exercise 32.

Step 1. Follow closely Exercise 32. (The two students may trade work.)

\section{CHURNING RECORD.-Churning No}

This blank should be neatly and accurately filled out when the product is finished.

Condition of cream.

Pounds cream

Total pounds of fat

Temperature at which cream was ripened

Time to ripen

Length of time held at churning temperature

$\%$ of fat in cream when churned.

Kind and size of churn used.

Approximate fullness of churn

Temperature churned.

Time to churn.

Amount of color used.

Size of granules when churning stops

Temperature of buttermilk

Test

Amount of wash water.

Temperature of wash water

Amount of salt used.

Brine or dry salted.

Butter from churn hard or soft.

Pounds of butter

Pounds of overrun

$\%$ overrun

Work and observations by

Assisted by

Make special notes regarding this churning operation. 
OвJECT.-To see the effect of churning at a high chuming temperature and washing at a low temperature.

Apparatus.-Same as for other, churning exercises.

Step 1. Have temperature of cream at $58^{\circ}$ to $60^{\circ} \mathrm{F}$, rinse water $45^{\circ}$ to $50^{\circ}$.

\section{CHURNING RECORD.-Churning No.}

This blank should be neatly and accurately filled out when the product is finished.

Condition of cream. Pounds cream

Total pounds of fat

Temperature at which cream was ripened

Time to ripen

Length of time held at churning temperature

$\%$ of fat in cream when churned.

Kind and size of churn used.

Approximate fullness of churn

Temperature churned

Time to churn

Amount of color used.

Size of granules when churning stops

Temperature of buttermilk. Test

Amount of wash water.

Temperature of wash water

Amount of salt used.

Brine or dry salted.

Butter from churn hard or soft.

Pounds of butter

Pounds of overrun

$\%$ overrun

Work and observations by

Assisted by

Make special notes regarding this churning operation. 
Овлест.-To see the effects of a low churning temperature and a high washing temperature.

Apparatus.- Same as for other churning exercises.

Step 1. Have cream at $48^{\circ}$ to $50^{\circ} \mathrm{F}$.; rinse water $56^{\circ}$ to $58^{\circ}$.

Write fully the evil effects of the above practice.

\section{CHURNING RECORD.-Churning No}

This blank should be neatly and accurately filled out when the product is finished.

Condition of cream.

Pounds cream

Total pounds of fat

Temperature at which cream was ripened..

Time to ripen

Length of time held at churning temperature

$\%$ of fat in cream when churned.

Kind and size of churn used.

Approximate fullness of churn

Temperature churned.

Time to churn.

Amount of color used.

Size of granules when churning stops

Temperature of buttermilk

Test

Amount of wash water.

Temperature of wash water

Amount of salt used . .

Brine or dry salted.

Butter from churn hard or soft.

I'ounds of butter.

Pounds of overrun

Coverrun

Work and observations by

Assisted by

Make special notes regarding this churning operation. 
Овлест.-To determine the effect of churning very thick cream. Apparatus.-Same as for other churning exercises.

Step 1. Have cream 35 to 40 per cent fat.

\section{CHURNING RECORD.-Churning No.}

This blank should be neatly and accurately filled out when the product is finished.

Condition of cream Pounds creim

Total pounds of fat

Temperature at which cream was ripened

Time to ripen

Length of time held at churning temperature

$\%$ of fat in cream when churned.

Kind and size of churn used.

Approximate fullness of churn

Temperature churned.

Time to churn.

Amount of color used.

Size of granules when churning stops

Temperature of buttermilk. Test

Amount of wash water.

Temperature of wash water

Amount of salt used.

Brine or dry salted.

Butter from churn hard or soft.

Pounds of butter

Pounds of overrun

To overrun

Work and observations by

Assisted by

Make special notes regarding this churning operation. 
Grade

Date

(58) EXERCISE 37.

OВJECT.-To see the effects of over-working butter. Apparatus.--Same as in other churning exercises.

Step 1. Churn and otherwise care for the cream as in the first churning exercises until the butter is ready to work.

Step 2. Work butter until it seems to be worked enough; note its condition. Break a few lumps and note the grain. Then continue working, noting the condition of the butter every five revolutions of the worker. Continue working until the butter is much over-worked. 'Record data.

\section{Report.}

Well worked

Additional 5 revolutions

10 revolutions

15 revolutions

20 revolutions

25 revolutions

30 revolutions

35 revolutions

Make special notes regarding this churning operation. Make record on following page. 


\section{CHURNING RECORD.-Churning No.}

This blank should be neatly and accurately filled out when the product is finished.

Condition of cream Pounds cream

Total pounds of fat

Temperature at which cream was ripened

Time to ripen

Length of time held at churning temperature

$\%$ of fat in cream when churned.

Kind and size of churn used

Approximate fullness of churn

Temperature churned.

Time to churn

Amount of color used.

Size of granules when churning stops

Temperature of buttermilk.

Test

Amount of wash water

Temperature of wash water

Amount of salt used.

Brine or dry salted.

Butter from churn hard or soft...

Pounds of butter.

Pounds of overrun

$\%$ overrun

Work and observations by

Assisted by

Make special notes regarding this churning operation. 
Date

EXERCISE 38.

ОвJECT.-To note the effect of over-churning on the quality of the butter produced.

Apparatus.-Same as in other churning exercises.

Step 1. Proceed as in a regular churning until butter comes the size of corn grain. Then continue churning until the butter has collected in large masses. Finish churning operations as usual. Record data on the following page but make observations on this page.

1. What will be the effect on the keeping quality of the butter when over-churned?

2. What constituents of the butter will likely be raised in their percentage?

3. Will more or less working of the butter be required to remove the buttermilk from butter that has been over-churned?

4. Will the grain, or texture, be thus improved or would it be more "sialvy"?

5 . What caution would you give regarding the extent of churning for butter that is to be stored and shipped long distances? 
CHURNING RECORD.-Churning No...........

This blank should be neatly and accurately filled out when the product is finished.

Condition of cream Pounds cream

Total pounds of fat.

Temperature at which cream was ripened

Time to ripen

Length of time held at churning temperature

$\%$ of fat in cream when churned.

Kind and size of churn used.

Approximate fullness of churn

Temperature churned.

Time to churn.

Amount of color used.

Size of granules when churning stops

Temperature of buttermilk.

Test

Amount of wash water.

Temperature of wash water

Amount of salt used.

Brine or dry salted.

Butter from churn hard or soft.

Pounds of butter.

Pounds of overrun

$\%$ overrun

Work and observations by

Assisted by.

Make special notes regarding this churning operation. 
Овлест.-The effect of churning cream at different stages of ripening. Apparatus.- Same as for other churning exercises, with cream as described in the following note.

Note to Instructor.-Divide the class of students into about four groups, and have previously prepared four equal churnings of cream, part 1 , fresh unripened, part 2 , having .2 per cent of acidity, part 3 , with .4 per cent acidity, and part 4 , with as high as .7 per cent if possible. Have the cream all of the same percentage of fat and same temperature. Each group should churn the cream under the same conditions and in the same type of churn.

The data and results should be recorded on the following page. The differences in the churnings for the different groups should be recorded below.

\begin{tabular}{l|c|c|c|}
\hline \multicolumn{1}{c}{ Part No. } & $\begin{array}{c}\text { Time required for } \\
\text { churning }\end{array}$ & $\%$ fat in butter- \\
milk
\end{tabular}

1. Can you discover evidence of curds in any of the lots of butter after working?

2. Which lots would probably keep best, if stored for some time? 


\section{CHURNING RECORD.-Churning No.}

This blank should be neatly and accurately filled out when the product is finished.

Condition of cream. Pounds cream

Total pounds of fat

Temperature at which cream was ripened

Time to ripen

Length of time held at churning temperature.

$\%$ of fat in cream when churned.

Kind and size of churn used.

Approximate fullness of churn

Temperature churned.

Time to churn.

Amount of color used

Size of granules when churning stops

Temperature of buttermilk Test

Amount of wash water.

Temperature of wash water

Amount of salt used.

Brine or dry salted.

Butter from churn hard or soft.

Pounds of butter.

Pounds of overrun

\%overrun

Work and observations by

Assisted by

Make special notes regarding this churning operation. 
ОВJECT.-The scoring of butter.

Apparatus.-Several samples of butter; score card; butter triers; paper, etc. Step 1. Read carefully the score card and become thoroughly familiar with its points.

Step 2. Wipe trier carefully and insert into butter near centre of the package. Withdraw carefully, note condition of butter on the trier; also take the aroma of the sample.

Step 3. Take a part of the trier-full between the tongue and the roof of the mouth and let dissolve slowly, noting the flavor, salt, taints, etc. Record observations.

\section{Report.}

\begin{tabular}{|c|c|c|c|}
\hline & Perfect score & Student's score & Criticisms \\
\hline Flavor & 45 & & \\
\hline Body & 25 & & \\
\hline Color & 15 & . & \\
\hline Salt & 10 & $\ldots$ & .. \\
\hline Package & 5 & & $\ldots$ \\
\hline
\end{tabular}

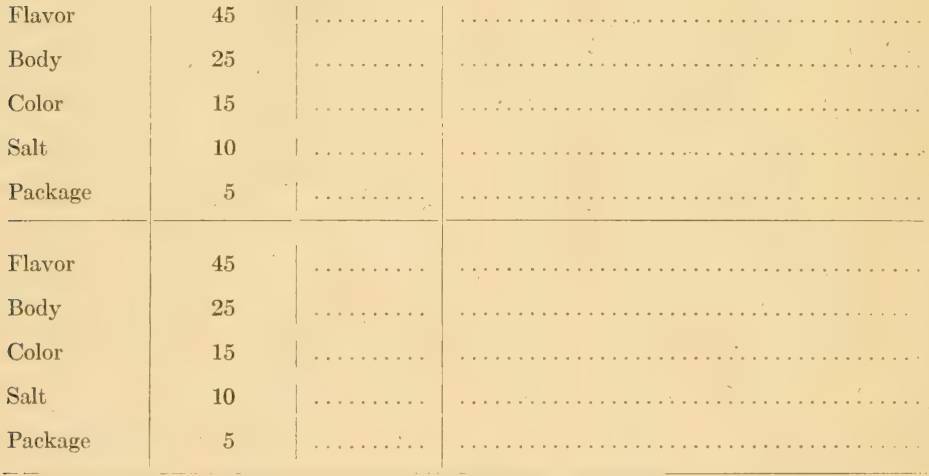

Give the reasons for the off flavors and defective body that may have been found in the above samples. 
Oв.JECT. - To determine the percentage of water in butter.

Apparatus.-Set of balances; samples of butter; some type of moisture test device as the Ames, Irish, or Marshall test.

Step 1. Put samples of butter in clean dry bottles or jars with tight lids or caps, warm up, but do not entirely melt the sample, until it can be thoroughly mixed. Mix.

Step 2. Carefully weigh out 10 grams of the sample into a heated, weighed dish or cup; heat over the flame or in an oven at $175^{\circ}$ to $180^{\circ} \mathrm{F}$., until it ceases to lose weight.

Step. 3. Take the difference between original weight and final weight and compute the percentage of moisture.

Report.

\begin{tabular}{|c|c|c|c|c|}
\hline & Original weight & Final weight & Loss in weight & $\%$ of moisture \\
\hline Sample No. $1 ., \ldots \ldots$ & & 1 & & \\
\hline Sample No. 2 . & & & & \\
\hline 'Sample No. $3 \ldots$... & & & & \\
\hline Sample No. $4 \ldots$ & & & & \\
\hline
\end{tabular}


Date. . . .

(66) EXERCISE 42.

\section{Cottage Cheese}

Use good skimmilk direct from separator. Heat to $75^{\circ}$ or $80^{\circ}$, in cans or vat. After the required temperature has been reached add starter, two to eight pounds per 100 pounds milk, the more starter used the quicker it will set. As soon as it is set or coagulated heat it slowly up to $95^{\circ}$.

If a dry cheese is desired heat up to $100^{\circ}$ or $108^{\circ}$, but if a moist cheese is desired heat only to $90^{\circ}$ or $93^{\circ}$. The object of heating is to aid in expelling the whey. The curd will settle to the bottom of the can. Transfer the contents of the can or vat on to a strainer or into a cheese cloth bag and let excess whey drain off. Stir curd occasionally so that it does not dry next to cloth or strainer.

As soon as the whey is properly drained off, salt by using 1 pound of salt to 100 pounds of curd. It is best not to salt cottage cheese too heavily as most people would rather salt to satisfy their taste. Salt retains the keeping quality of cottage cheese.

Write full description of cheese made and note any special changes observed. 

Grade.

Date. .

$(70)$

EXERCISE 43.

\section{Cross Section of Cream Separator Bowl}

Note.-Select any typical cream separator and draw to a suitable scale an accurate cross section of the bowl. Neatly label all parts. In addition to this trace carefully the inflow of whole milk, thru the area of separation and thru the outflow of cream and skimmilk. Any explanations necessary to make this drawing clear should be made at bottom of page. 
1. What is the percentage of total solids in milk testing 4.9 and having a lactometer reading of 33 at $57^{\circ} \mathrm{F}$.?

2. What would be the correct specific gravity of a sample of milk if the lactometer gave a reading of 32.5 at $65^{\circ} \mathrm{F}$.?

3. What is condition of each of the following samples:

(a) Lactometer reading 32 at $58^{\circ} \mathrm{F}$., and has 4 per cent fat.

(b) Lactometer reading 33 at $63^{\circ} \mathrm{F}$., and has 2.5 per cent fat.

(c) Lactometer reading 27.4 at $69^{\circ} \mathrm{F}$., and has 2.4 per cent fat.

4. How many pounds of solids not fat in 139 pounds of milk testing 3.9 per cent fat and having a lactometer reading of 29 at $69^{\circ} \mathrm{F}$.?

5. How many pounds of total solids are there in 49 pounds of milk having a fat test of 4.17 per cent and a lactometer reading of 32.4 at $56^{\circ} \mathrm{F}$.?

6. How many pounds of milk testing 3 per cent must be mixed with 140 pounds cream, testing 27 per cent, to make milk testing 5.1 per cent?

7. Two thousand pounds of milk testing 3.5 per cent fat, is to be made to test 4 per cent by adding milk that tests 5 per cent. How many pounds will be added?

8. One thousand pounds of cream testing 30 per cent is to be reduced to 20 per cent by adding whole milk testing 4 per cent. How many pounds of the milk must be added?

9. One thousand pounds of cream testing 30 per cent is to be reduced to 25 per cent by adding milk testing 2.5 per cent. How many pounds of the milk must be added?

10. One thousand pounds of cream testing 30 per cent is to be reduced to 25 per cent by adding skimmilk. How many pounds of skimmilk must be added?

11. Six hundred pounds of 30 per cent cream is wanted. Having cream on hand testing 40 per cent, and skimmilk, find how many pounds of each are needed to produce 600 pounds of 30 per cent cream.

12. How many pounds each of 50 per cent cream and 25 per cent cream must be mixed together to produce 1,000 pounds of cream testing 40 per cent?

13. One thousand pounds of cream testing 50 per cent is to be diluted to make it test 40 per cent, using cream testing 25 per cent. How many pounds of the 25 per cent cream must be added to give the desired test?

14. One thousand pounds of cream testing 25 per cent is to be raised to 40 per cent with cream testing 50 per cent. Find how many pounds of the 50 per cent cream must be added to the 25 per cent cream to make it test 40 per cent. 
15. Received 800 pounds of butterfat in 20,000 pounds of 4 per cent milk. From this 975 pounds of butter was made. Find the true overrun, expressed both in percentage and in pounds.

16. Received 800 pounds butterfat which made 984.94 pounds of butter: allowing 1 per cent for mechanical losses, what was the percentage of overrun, after mechanical losses were deducted?

17. Received 800 pounds butterfat. Made 984.94 pounds butter. Loss 1.25 per cent. What was the overrun?

18. Butterfat received 800 pounds; butterfat in butter made 80.41 per cent. What is the overrun?

19. What is the percentage of overrun when 176 pounds fat makes 194 pounds butter? What is the percentage of fat in this butter?

20. What is the percentage of overrun if 1800 pounds of cream testing 33 per cent makes 667 pounds of butter.

21. If you had 15 pounds of butterfat in cream that is to be churned and 18 pounds of butter was made, what is the percentage of overrun?

22. If 1800 pounds of cream testing 33 per cent made 650 pounds of butter, what is the number of pounds overrun? The percentage of overrun?

23. How many pounds of butter would you get from 1000 pounds of cream, testing 23 per cent and having an overrun of 14 per cent?

24. When butterfat sells for 40 cents per pound, how much must be secured for 4 per cent milk wholesale to realize the same? Buttermilk and skimmilk selling for 25 cents per hundred.

25. From which of these methods of selling will the largest returns be secured? (a) 4 per cent milk at $\$ 1.55$ per hundred; (b) 20 per cent cream selling for 80 cents per gallon, with skimmilk worth 25 cents per hundred; (c) butter selling for 40 cents per pound, buttermilk and skimmilk at 25 cents per hundred, and an overrun of 18 per cent being secured; charges for butter manufacture being one and one-half cents per pound of butter. 




$$
\text { , }
$$






